\title{
Mechanical Behavior and Microstructural Analysis of NiTi-40Au Shape Memory Alloys Exhibiting Work Output Above $400{ }^{\circ} \mathrm{C}$
}

Lee Casalena*a, Glen S. Bigelow ${ }^{b}$, Yipeng Gao ${ }^{a}$, Othmane Benafan ${ }^{b}$, Ronald D. Noebe $^{b}$, Yunzhi Wang ${ }^{a}$, Michael J. Mills ${ }^{a}$.

Intermetallics (2017)

${ }^{a}$ The Ohio State University, Center for Electron Microscopy \& Analysis, Department of Materials Science \& Engineering 1305 Kinnear Rd, Suite 100, Columbus, OH, 43212, USA

${ }^{b}$ NASA Glenn Research Center, Materials and Structures Division 21000 Brookpark Rd. Cleveland, OH, 44135, USA

casalena.1@osu.edu*

glen.s.bigelow@nasa.gov

gao.108@osu.edu

othmane.benafan@nasa.gov

ronald.d.noebe@nasa.gov

wang.363@osu.edu

mills.108@osu.edu 


\section{Abstract}

Substituting $\mathrm{Ni}$ with $\mathrm{Au}$ in $\mathrm{NiTi}$ leads to dramatic increases in transformation temperatures, meeting one of the requirements for a viable high temperature actuator material. Consequently, four alloys containing between 49 and 51 at.\% Ti, a fixed 40 at.\% $\mathrm{Au}$, and balance $\mathrm{Ni}$, were prepared and investigated in detail using load-biased thermal cycling (LBTC), scanning electron microscopy (SEM), aberration corrected scanning transmission electron microscopy (STEM), and X-ray energy dispersive spectroscopy (XEDS). LBTC experiments demonstrated work output well above $400{ }^{\circ} \mathrm{C}$, with full recovery up to $100 \mathrm{MPa}$. The alloys exhibit minimal variation in shape memory properties despite the relatively large composition range from Ti-lean to Ti-rich, in stark contrast to most other NiTi-based systems, which demonstrate extreme compositional sensitivity. Electron beam analysis revealed the presence of two types of secondary phases present in all compositions, which are subsequently characterized. Differences in secondary phase content as a function of alloy composition is shown to have a moderating effect on the transforming matrix composition - an important asset for this alloy system - potentially easing processing requirements and opening up shape memory alloys to new fabrication techniques. Unrecovered strain during cycling at higher loads is analyzed from a theoretical perspective to gain insight into the mechanisms of defect formation responsible for functional fatigue.

\section{Intermetallics-specific Keywords}
A: shape-memory alloys
B: precipitates
B: shape-memory effects
D: microstructure
$\mathrm{E}$ : mechanical properties, theory
G: shape-memory alloy applications (actuators, couplings, etc.) 


\section{Graphical Abstract}
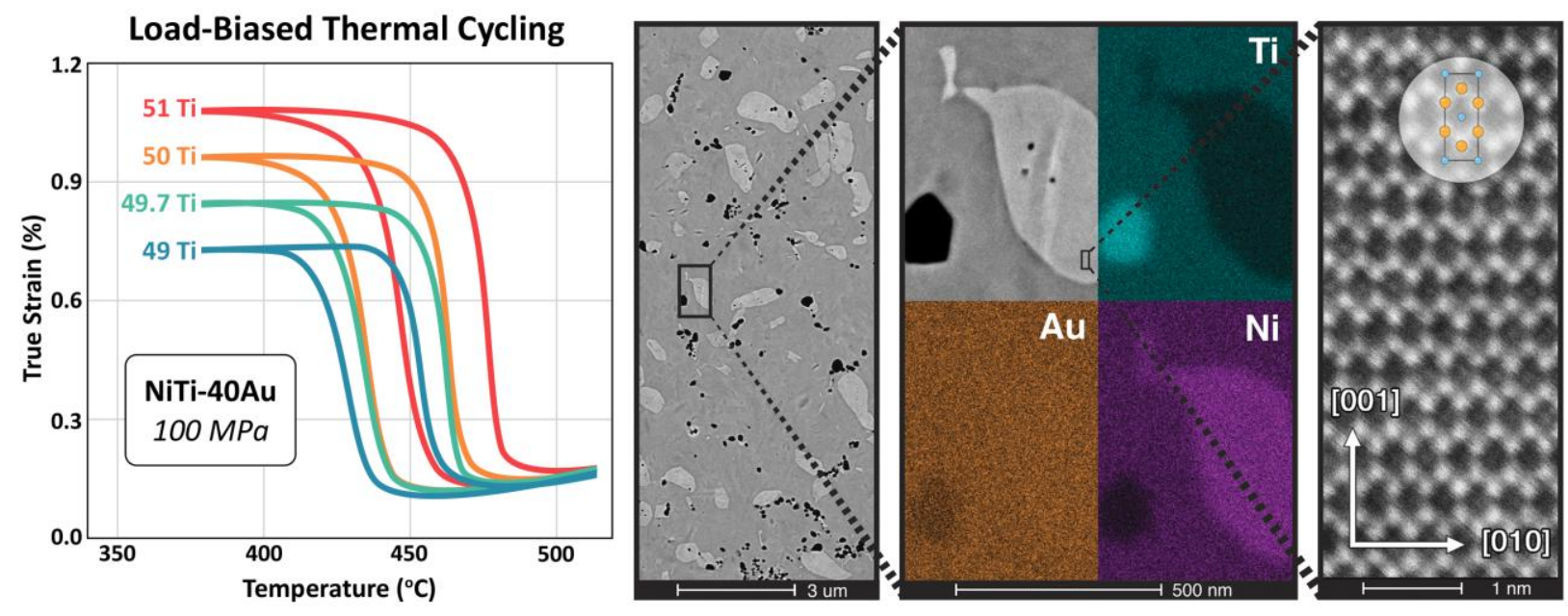


\section{Introduction}

While NiTi boasts a favorable balance of properties, its operating environment is limited by its low martensitic transformation start temperature $\left(M_{\mathrm{s}}\right)$, reducing the potential applications of an otherwise extremely versatile material. Consequently, the search for viable high temperature shape memory alloys continues, driven primarily by the aerospace and automotive industries, where applications such as solid-state shape memory actuators could potentially reduce weight and increase efficiency by replacing traditional actuation systems. Addition of $\mathrm{Hf}, \mathrm{Zr}, \mathrm{Pt}, \mathrm{Pd}$, or $\mathrm{Au}$ to NiTi has been shown to increase $M_{\mathrm{s}}$, but at the same time higher temperatures weaken resistance to plasticity, creep, and transformation-induced defect generation, significantly increasing the challenge to high temperature shape memory alloy (HTSMA) development $[1,2]$. Of the various HTSMAs, the NiTiAu system has received very little research attention, particularly for high Au compositions. The high cost of Au obviously poses a barrier for many applications, however budding micro-electro-mechanical systems (MEMS) and devices composed of fine wires [3] - where the actual raw material cost is minimal compared to that of the final system - may benefit significantly from such alloys.

In 1970, Donkersloot and Van Vucht [4] were first to demonstrate the high temperature reversible martensitic transformation that occurs in the TiAu system between a high temperature B2 cubic phase and a low temperature B19 orthorhombic phase. They tested 6 compositions varying from 40 at.\% to 52.5 at.\% Au using XRD to determine lattice parameters and transformation temperatures, revealing a stress-free $M_{\mathrm{s}}$ as high as $630^{\circ} \mathrm{C}$. On the other end of the composition spectrum, Eckelmeyer et al. [5] demonstrated that substituting just 2 at.\% of the $\mathrm{Ni}$ in NiTi for Au was effective in increasing $M_{\mathrm{s}}$ by $40^{\circ} \mathrm{C}$. These results were encouraging, since the majority of ternary element additions to NiTi reduced $M_{\mathrm{s}}[5]$.

Wu \& Wayman. [6-8] probed the NiTiAu system using TEM and electrical resistivity measurements. Additions of 5, 10, 40, and 50 at.\% Au were made in place of $\mathrm{Ni}$, while maintaining $\mathrm{Ti}$ at 50 at.\%. The authors confirmed the B2 and B19 structures in the 40 and 50 at.\% alloys. Bend and free-recovery tests were used to demonstrate a one-way SME in both alloys, with complete recovery of up to $3 \%$ when deformed at 
room temperature, but no two-way SME could be induced through training. These results were quite modest compared with Hosoda et al. [9], who demonstrated 10.75\% free recovery in $\mathrm{Ti}_{47} \mathrm{Au}_{53}$, and Besseghini et al. [10], who showed $8 \%$ free recovery in $\mathrm{Ti}_{50} \mathrm{Ni}_{36.2} \mathrm{Au}_{13.8}$.

Unfortunately, free recovery methods of testing are not relevant to the design of actuators, where, by definition, a force is exerted against some external load, thereby doing work. Noebe et al. [11] have demonstrated that NiTiPt alloys with similar freerecovery behavior can have disparate work behavior under a bias-load and therefore has no correlation to potential work output. Load-biased, or constant force thermal cycling [12] has become the benchmark testing method for these types of applications, since a high $M_{\mathrm{s}}$ is of little use if work cannot be produced during the transformation.

In this paper, load-biased thermal cycling (LBTC) and advanced characterization capabilities are applied to several Ti-rich and $\mathrm{Au}(\mathrm{Ni})$-rich $\mathrm{NiTi}-40 \mathrm{Au}$ alloys. The microstructural analyses have revealed many previously unknown details on several phases in this alloy system. This insight is also correlated with the first load-biased thermal cycling experiments to be performed on these alloys, indicating some very promising initial results for very high-temperature applications. 


\section{Experimental Methods}

Four alloys with target compositions 49Ti-11Ni-40Au, 49.7Ti-10.3Ni-40Au, 50Ti$10 \mathrm{Ni}-40 \mathrm{Au}$, and $51 \mathrm{Ti}-9 \mathrm{Ni}-40 \mathrm{Au}$ were prepared by vacuum induction melting high purity elements using graphite crucibles. The melts were cast into a cylindrical copper chill mold ( $25.5 \mathrm{~mm}$ diameter by $\sim 102 \mathrm{~mm}$ long) with an appropriate hot-top to accommodate shrinkage during solidification. The resulting ingots were homogenized for 72 hours at $1050{ }^{\circ} \mathrm{C}$ and furnace cooled, followed by extrusion at $900{ }^{\circ} \mathrm{C}$ with a reduction ratio of 7:1. Cylindrical dog-bone shaped tensile specimens $(5.08 \mathrm{~mm}$ in diameter and 15.25 $\mathrm{mm}$ in gage length) were machined from the extruded rods. Smaller cylindrical samples (9 $\mathrm{mm} \times 5 \mathrm{~mm}$ ) were also cut from the extrusion rods and used for thermo-mechanical testing and microstructural analysis. Each of the four alloys had an $M_{\mathrm{s}}$ between $400{ }^{\circ} \mathrm{C}$ and $500{ }^{\circ} \mathrm{C}$ in the as-extruded condition, characterized by both differential scanning calorimetry (DSC) and differential thermal analysis (DTA) methods.

Load-biased (constant force) thermal cycling tests were performed for all four compositions in tension and compression, using an MTS 810 servo-hydraulic load frame equipped with a FlexTest multi-channel digital controller. Temperature was cycled between $100{ }^{\circ} \mathrm{C}$ and $580{ }^{\circ} \mathrm{C}$ at fixed stresses of $0 \mathrm{MPa}$ to $350 \mathrm{MPa}$ in tension and 0 $\mathrm{MPa}$ to $500 \mathrm{MPa}$ in compression, varied in $50 \mathrm{MPa}$ increments. Strains in tension were measured using a $12.7 \mathrm{~mm}$ gage, high-temperature extensometer. In compression, strains were calculated via measurement of the displacement of the aged ME3 alloy platen faces with a Micro-Epsilon optoControl optical micrometer. Temperature was varied at a rate of $20^{\circ} \mathrm{C} / \mathrm{min}$, controlled using an Eurotherm temperature controller with a NovaStar $7 \mathrm{KW}$ induction heating system and water-cooled grips.

Bulk samples for scanning electron microscopy (SEM) were cut using a Struers Accutom-50 high speed saw and polished to a final step consisting of $0.25 \mu \mathrm{m}$ diamond suspension. It should be noted that sample surfaces did not respond well to vibratory polishing with colloidal silica. TEM samples were trenched, plucked, and thinned to electron transparency using an FEI Nova 600 NanoLab focused ion beam (FIB). Resulting FIB damage was removed by argon ion milling on a Fischione 1040 Nanomill. Bulk metallic chemical analysis of all four compositions was performed via 
Inductively Coupled Plasma-Atomic Emission Spectroscopy (ICP-AES) and trace impurities were measured via a LECO C/S and N/O analyzers. Metallic elements were normalized to 99.9 wt.\% before conversion to atomic percent. Compositions for each alloy are listed in Table 1.

\begin{tabular}{|c|c|c|c|c|c|c|}
\hline \multicolumn{7}{|c|}{ Table 1: Chemical analysis of four NiTi-40Au alloys. } \\
\hline Target Composition (at \%) & \multicolumn{3}{|c|}{$\begin{array}{c}\text { Measured Composition } \\
\text { (at \%) }\end{array}$} & \multicolumn{3}{c|}{ Measured Impurities (wt. \%) } \\
& $\mathrm{Ni}$ & $\mathrm{Ti}$ & $\mathrm{Au}$ & $\mathrm{C}$ & $\mathrm{N}$ & 0 \\
\hline & 9.03 & 50.53 & 40.44 & 0.086 & $<0.0001$ & 0.014 \\
\hline $\mathrm{Ni}_{9} \mathrm{Ti}_{51} \mathrm{Au}_{40}$ & 10.09 & 49.39 & 40.52 & 0.053 & 0.0000 & 0.015 \\
\hline $\mathrm{Ni}_{10} \mathrm{Ti}_{50} \mathrm{Au}_{40}$ & 10.57 & 48.96 & 40.47 & 0.058 & 0.0000 & 0.017 \\
\hline $\mathrm{Ni}_{10.3} \mathrm{Ti}_{49.7} \mathrm{Au}_{40}$ & 11.18 & 48.73 & 40.09 & 0.059 & $<0.0001$ & 0.019 \\
\hline $\mathrm{Ni}_{11} \mathrm{Ti}_{49} \mathrm{Au}_{40}$ & & & & &
\end{tabular}

Scanning electron microscopy (SEM) and SEM-level X-ray energy dispersive spectroscopy (XEDS) analyses were performed on a FEI Sirion field emission SEM and a FEI Quanta 200 SEM at $30 \mathrm{kV}$. Structural analysis was conducted using a Phillips/FEI CM200 transmission electron microscope (TEM). Atomic resolution imaging was performed using high-angle annular dark-field (HAADF) mode on a probe-corrected FEI $\operatorname{Titan}^{3}$ 80-300 scanning transmission electron microscope (STEM) at $300 \mathrm{kV}$. Highresolution XEDS was performed using a four-quadrant SuperX-EDS detector system on an image-corrected FEI Titan ${ }^{3}$ G2 60-300 STEM. 


\section{Results}

\subsection{Load-biased shape memory behavior}

Results from load-biased thermal cycling experiments in tension and compression are shown in Figures 1 and 2, respectively. Solid lines represent, while dashed lines represent cooling. Behavior across the four compositions was relatively similar. All alloys exhibited transformation temperatures above $400{ }^{\circ} \mathrm{C}$ and there was minimal residual strain at stresses below about $150 \mathrm{MPa}$. However, the transformation strains were somewhat limited. Also, the 49Ti alloy fractured on loading to $350 \mathrm{MPa}$. All alloys survived testing in compression to $500 \mathrm{MPa}$, however significant residual strain was observed at stresses greater than about $300 \mathrm{MPa}$. The most significant portion of this residual strain appeared to be plastic deformation/creep of all four alloys at temperatures around $500{ }^{\circ} \mathrm{C}$ and stresses above $300 \mathrm{MPa}$. This is most clearly observed in the compression response shown in Figure 2. 

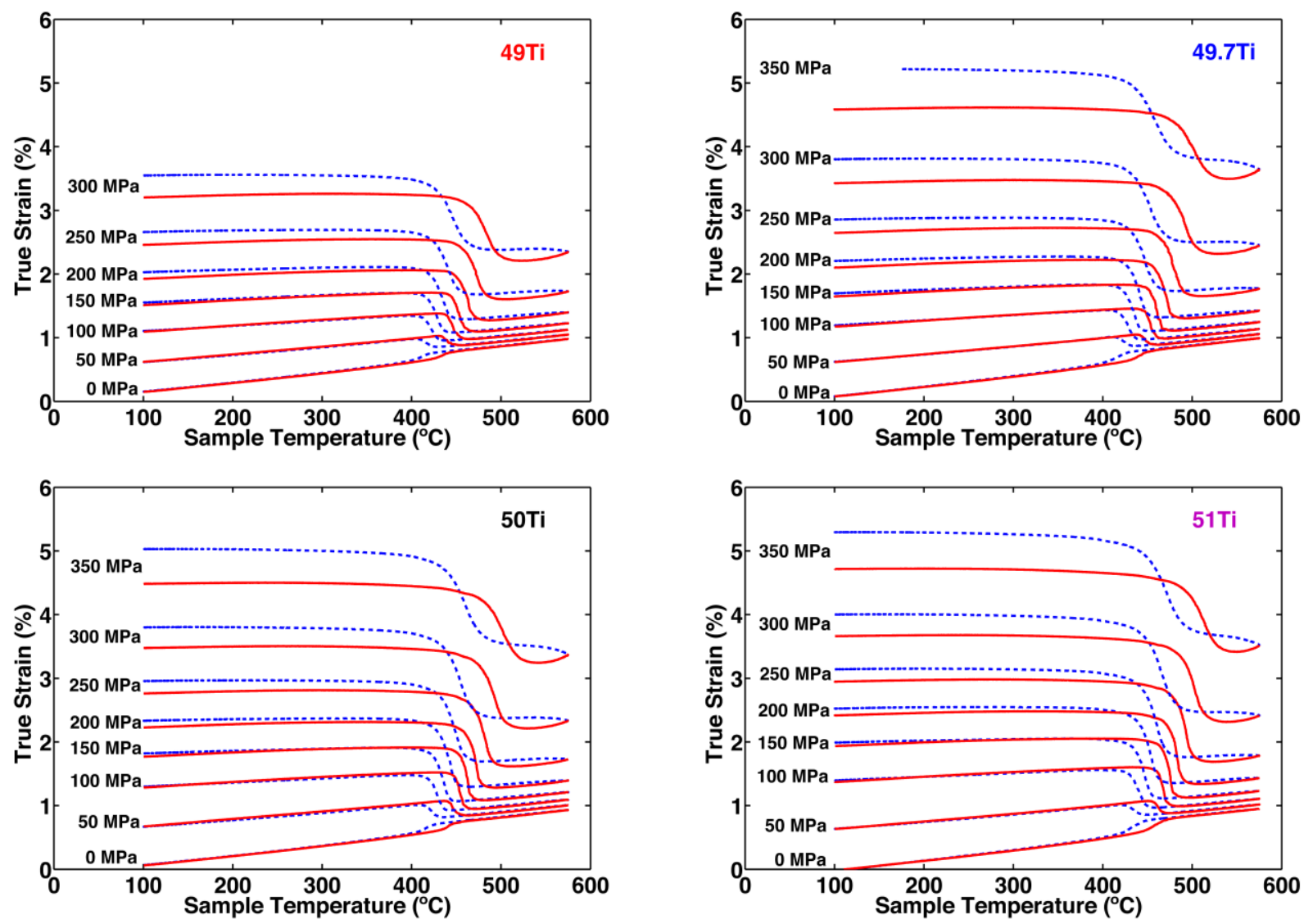

Figure 1: Results of load-biased thermal cycling experiments in tension on four NiTi-40Au alloys. Solid lines represent heating, while dashed lines represent cooling. 

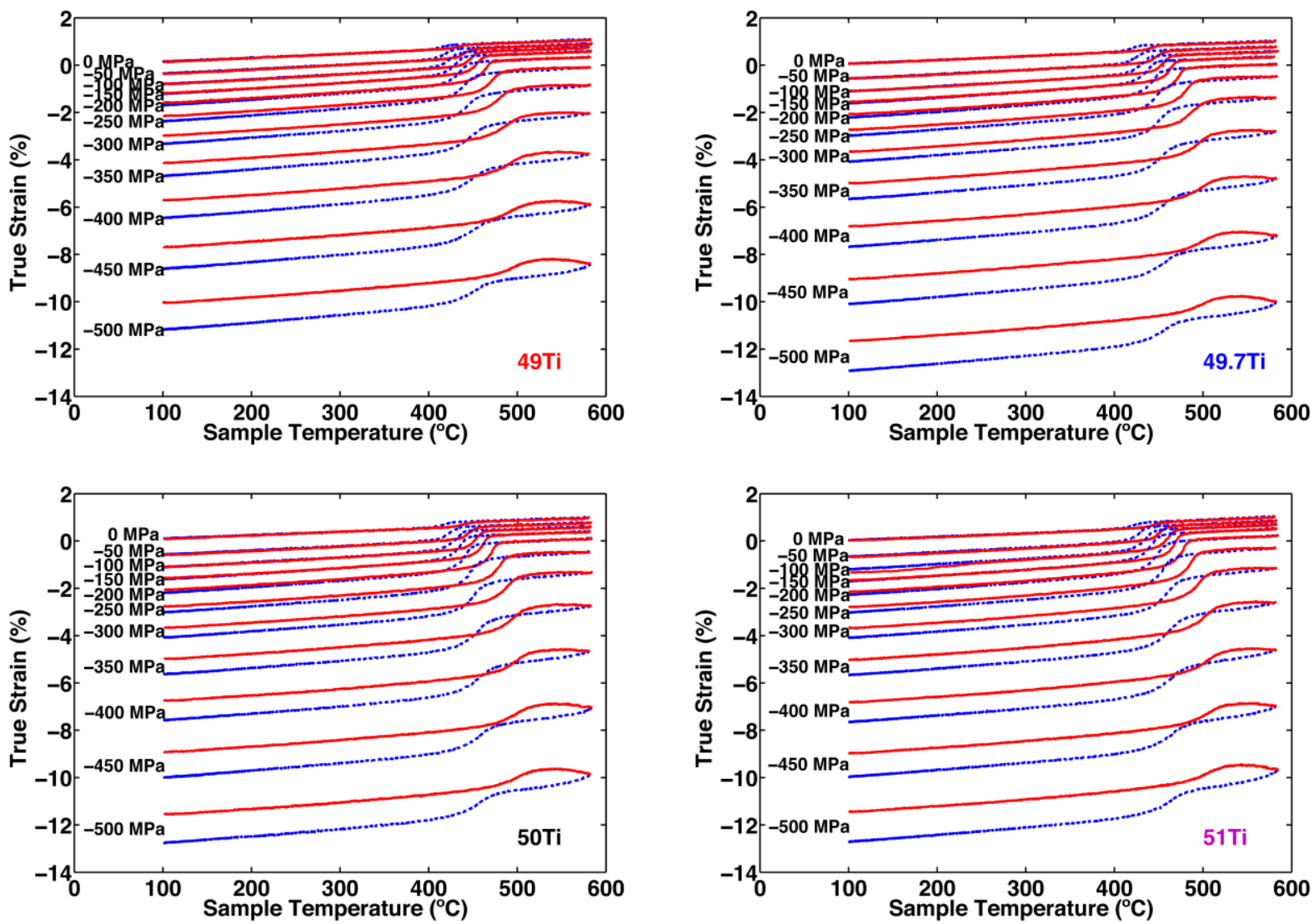

Figure 2: Results of load-biased thermal cycling experiments in compression on four NiTi-40Au alloys. Solid lines represent heating, while dashed lines represent cooling. 
Figure 3 shows the $150 \mathrm{MPa}$ loading response of each alloy, shifted in strain so that all tension samples and compression samples started at the same upper cycle temperature strain point, for a better comparison of actual strain-temperature response. While it is remarkable to achieve work output at such high temperatures, the magnitude of the work output is relatively low as a result of the modest transformation strains, with the $51 \mathrm{Ti}$ alloy exhibiting the largest transformation strain and thus a slightly higher work output compared to the other alloys. However, given the relatively large range of $\mathrm{Ti}$ and $\mathrm{Ni}$ content between the alloys, there is a remarkable similarity in behavior, which is not observed in other NiTi-based systems [2].

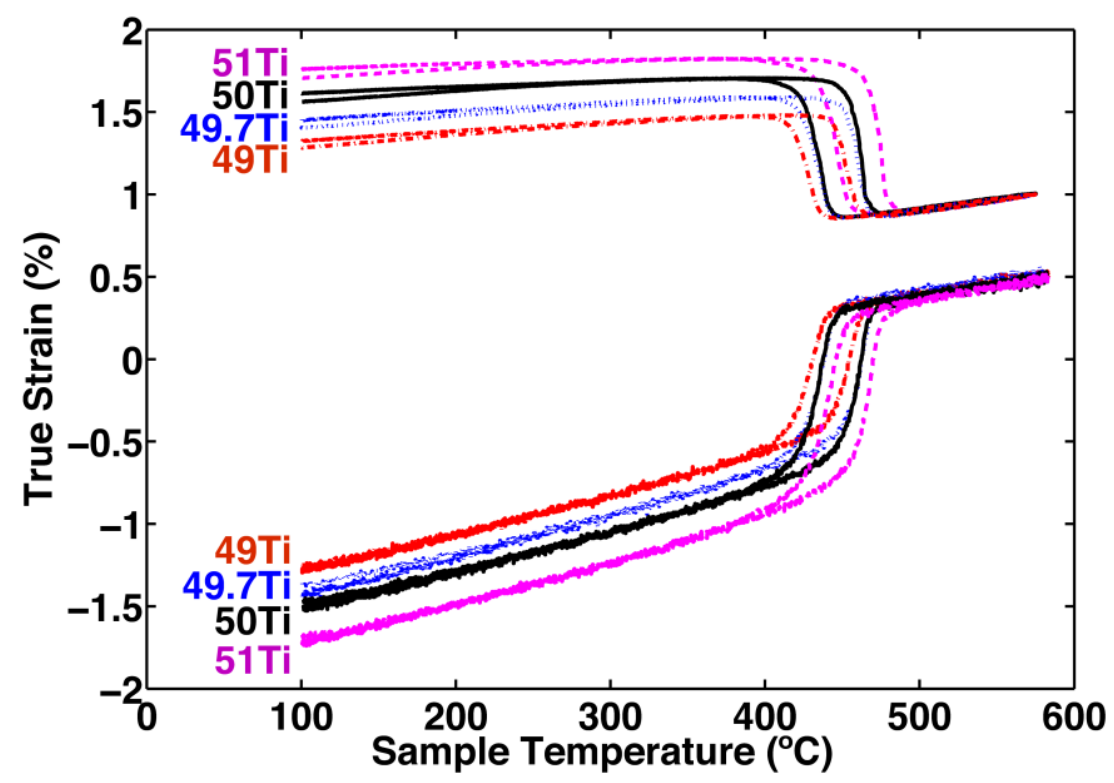

Figure 3: Load-biased thermal cycling results for all 4 NiTiAu alloys at $150 \mathrm{MPa}$ with respective tension and compression curves shifted to the same upper cycle temperature strain for direct comparison of the responses. 

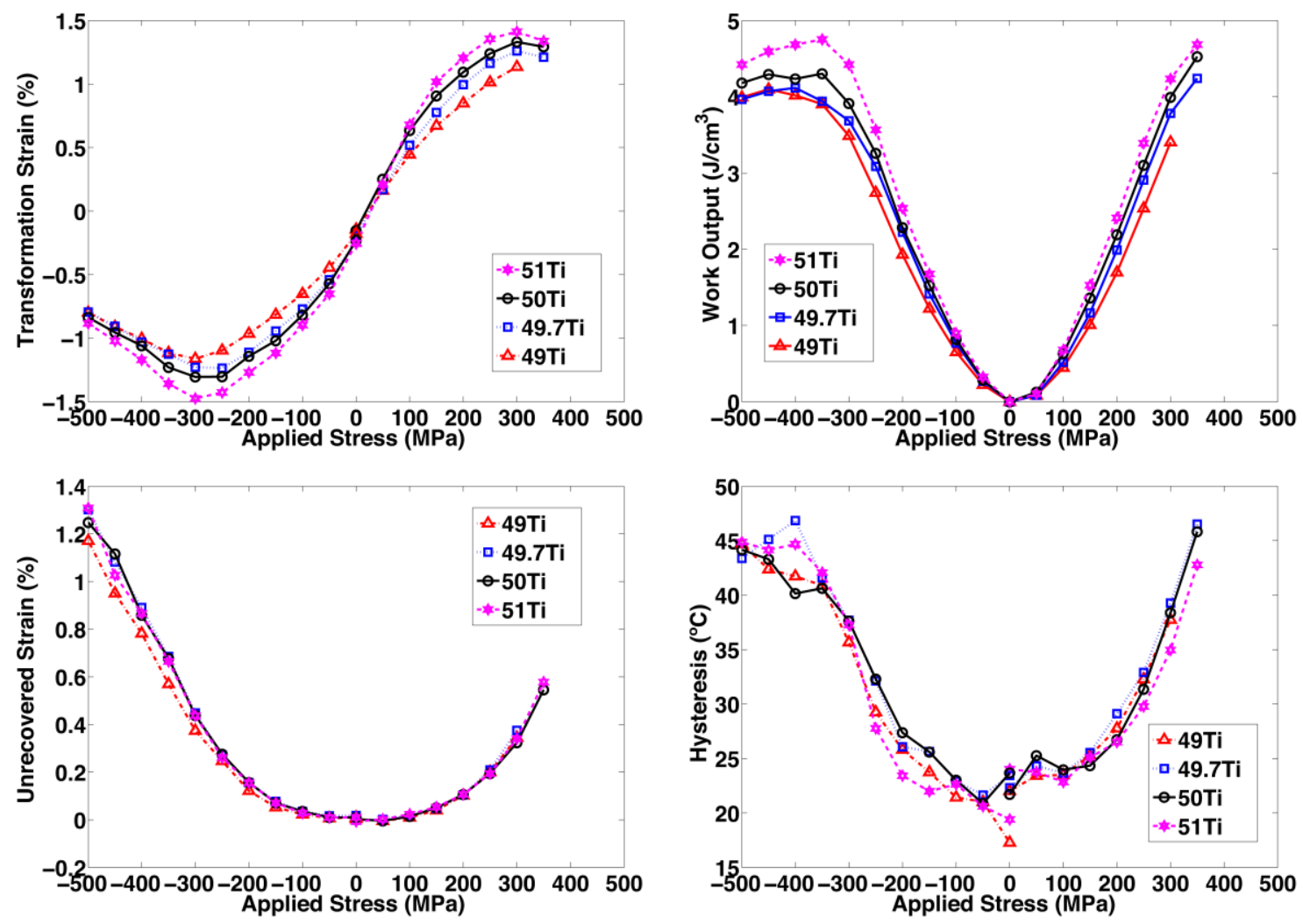

Figure 4: Comparisons of work output, transformation strain, unrecovered strain, and hysteresis as a function of stress for the four NiTiAu alloys.

Key load-biased shape memory properties for all four alloys namely work output, transformation strain, unrecovered strain, and hysteresis are summarized in Figure 4. With decreasing Ti content, there is a slight decrease in transformation strain across the alloys, especially between $100-300 \mathrm{MPa}$ tensile or compressive stress. Consequently, there is also a slight influence of composition on work output, but the effect is minimal compared to other NiTi-based shape memory alloys. Also remarkably, the current set of alloys exhibit nearly identical behavior in tension and compression, as opposed to other binary and high temperature shape memory alloys, which exhibit highly anisotropic behavior in tension and compression [2, 13, 14]. In this set of alloys, transformation 
strain increases with stress and peaks at $300 \mathrm{MPa}$ with $1.41 \%$ and $-1.47 \%$ for the $51 \mathrm{Ti}$ alloy, and $1.14 \%$ and $-1.16 \%$ for the $49 \mathrm{Ti}$ alloy, respectively in tension and compression. In compression, a high enough stress is reached to determine the peak work output, which occurs at $-350 \mathrm{MPa}\left(4.75 \mathrm{~J} / \mathrm{cm}^{3}\right)$ for the $51 \mathrm{Ti}$ alloy, and at $-450 \mathrm{MPa}$ $\left(4.1 \mathrm{~J} / \mathrm{cm}^{3}\right)$ in the $49 \mathrm{Ti}$ alloy. In tension, the work output for all four samples increases with stress over the range tested due to the manner in which work output is calculated. At $350 \mathrm{MPa}$, the $51 \mathrm{Ti}$ alloy achieved a work output of $4.68 \mathrm{~J} / \mathrm{cm}^{3}$ and at $300 \mathrm{MPa}$, the 49Ti alloy achieved $3.40 \mathrm{~J} / \mathrm{cm}^{3}$. Unrecovered strain is negligible for all alloys below 100 $\mathrm{MPa}$ at only $0.03 \%$ and $0.016 \% /$ cycle in compression and tension, respectively. Hysteresis is particularly small, less than $25{ }^{\circ} \mathrm{C}$ below about $150 \mathrm{MPa}$ for both tension and compression. Consequently, the alloys show promise for use at temperatures above $400{ }^{\circ} \mathrm{C}$ for at least limited actuation cycles at stresses at or below $150 \mathrm{MPa}$. 


\subsection{Microstructural analysis}

Room-temperature XRD measurements, shown in Figure 5, confirmed an orthorhombic B19 martensite matrix for all four alloys in the as-extruded condition. This agrees with previous literature for the 50Ti alloy [6]. The measured lattice parameters $a$ $=0.289 \mathrm{~nm}, \boldsymbol{b}=0.458 \mathrm{~nm}$, and $\boldsymbol{c}=0.478 \mathrm{~nm}$, do not vary significantly between the four alloys, suggesting a moderated matrix composition, discussed in greater detail in section 4.3. Typical martensite morphology is shown in Figure 6 for the 49-Ti alloy. Figure 6a shows a lower magnification micrograph of B19 martensite plates of different dimensions, while Figure $6 \mathrm{~b}$ shows the internal twinning within a plate, where the individual atomic planes can be seen in one set of twins aligned with the electron beam.

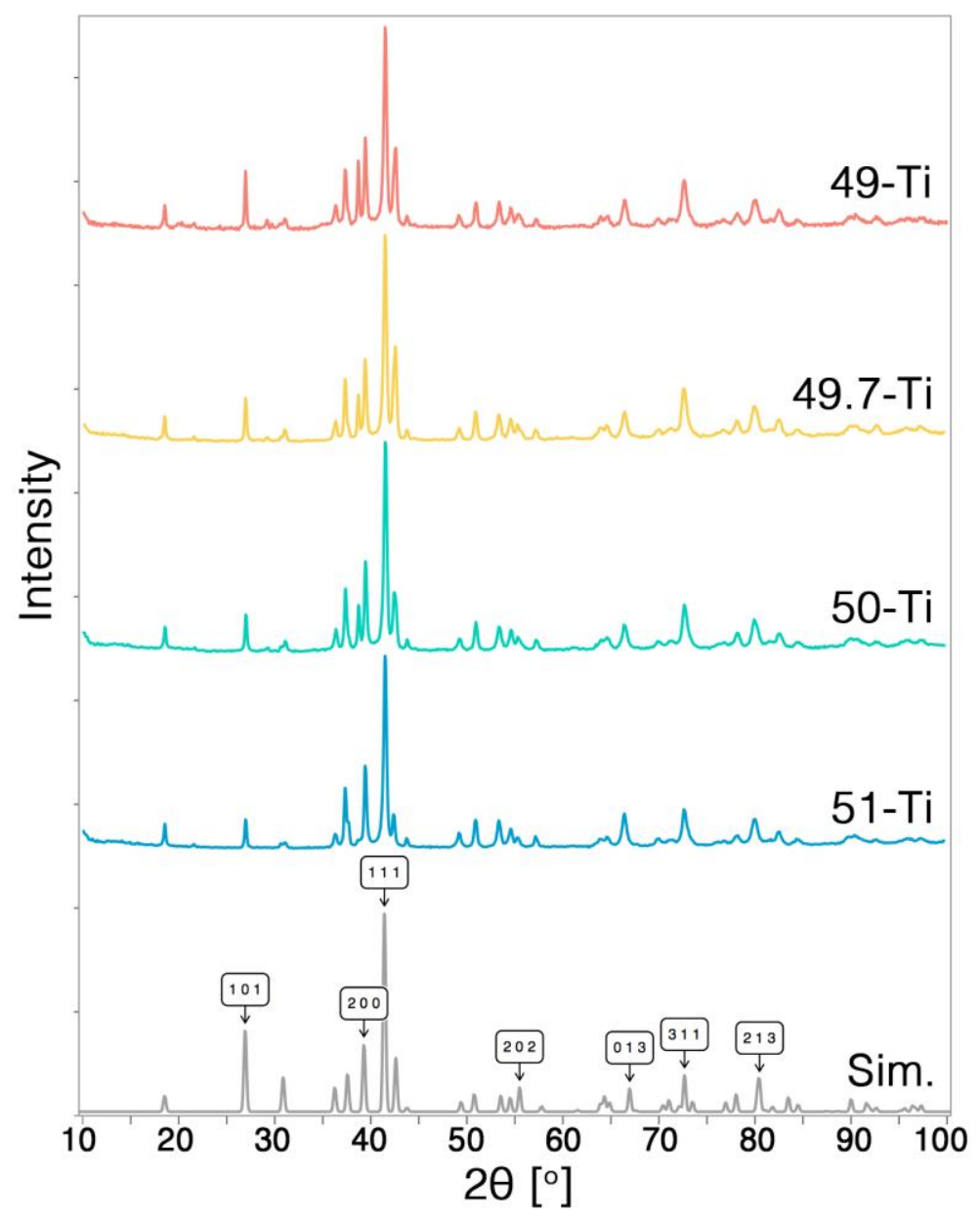

Figure 5: XRD spectra for all four alloys in the as-extruded condition compared with a B19 martensite simulation, showing a close match with little variation between alloys. 

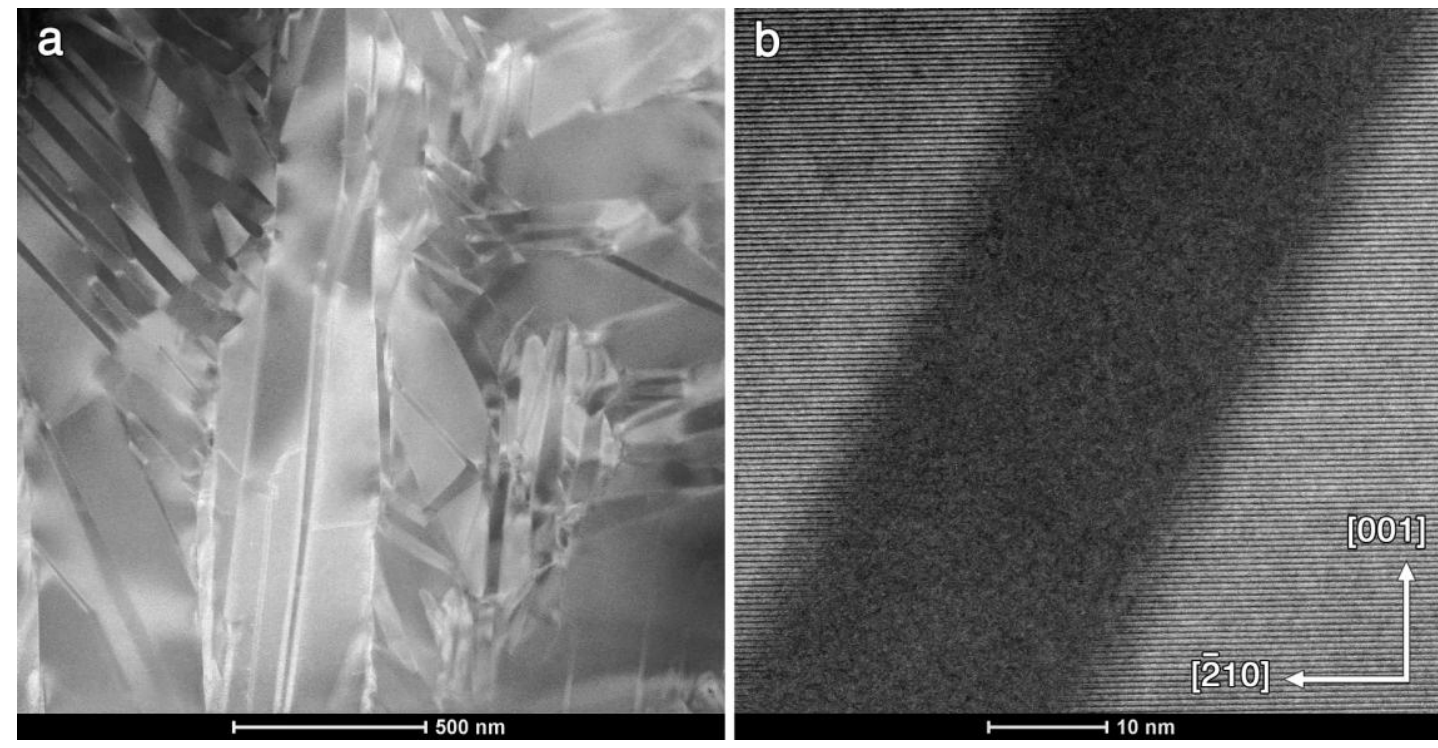

Figure 6: (a) Dark-field STEM micrograph showing the B19 martensite matrix morphology in the 49Ti alloy. (b) High resolution HAADF STEM micrograph of the internal twins within a martensite plate, with one set aligned with the electron beam.

Polished bulk samples were analyzed using SEM in backscattered electron (BSE) mode. Figure 7a shows a transverse section (with respect to extrusion direction) micrograph of the 49Ti alloy. Two phases are clearly present within the B19 martensite matrix. Results of SEM-XEDS chemical mapping is shown in Figure 7b, where the variation in composition of the two phases can be seen. The dark phase labeled " 1 " is Ti-rich while the light phase labeled "2" is Ti-lean. Quantitative analysis using custom kfactor corrections showed phase 1 to have a 3:1 ratio of $\mathrm{Ti}$ to $\mathrm{Au}$, with negligible $\mathrm{Ni}$ content, suggesting that the phase is $\mathrm{Ti}_{3} \mathrm{Au}$. Phase 2 exhibited a 4:3:2 ratio of $\mathrm{Au}: \mathrm{Ti}: \mathrm{Ni}$, denoted as $\mathrm{Ti}\left(\mathrm{Au}_{0.66} \mathrm{Ni}_{0.33}\right)_{2}$, due to its structural similarity to $\mathrm{TiAu}_{2}$, as is further explained in section 3.2.2.

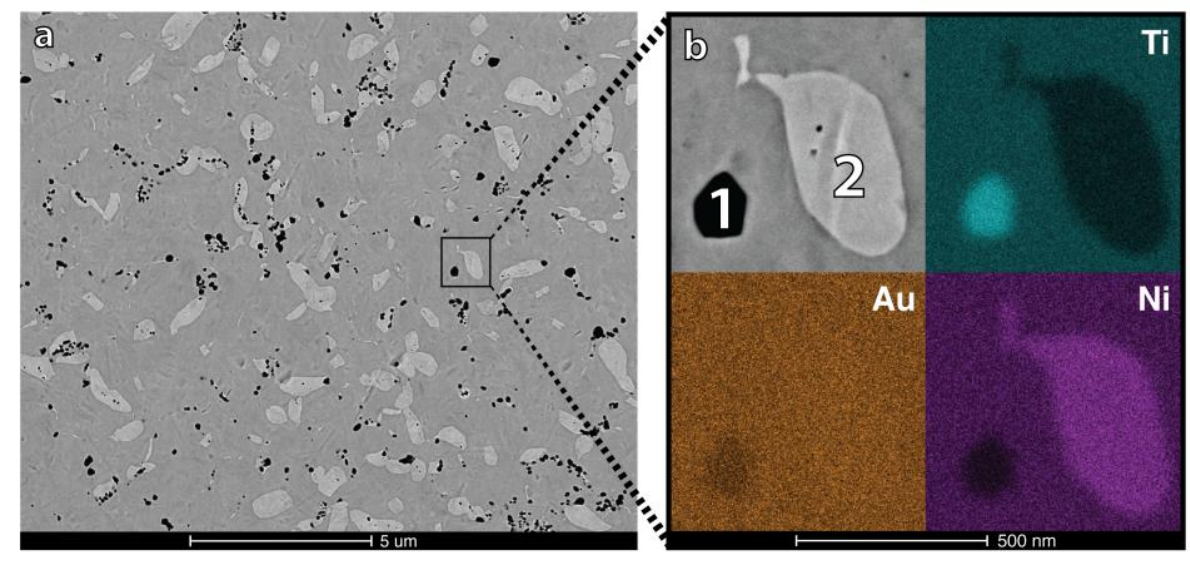

Figure 7: (a) Transverse section SEM-BSE micrograph of the as-extruded 49Ti alloy. (b) SEMXEDS chemical intensity maps showing $\mathrm{Ti}_{3} \mathrm{Au}$ labelled 1, and $\mathrm{Ti}\left(\mathrm{Au}_{0.66} \mathrm{Ni}_{0.33}\right)_{2}$ labelled 2. 
Figure 8 shows a longitudinal section SEM micrograph of the 49Ti alloy. The vertical axis is aligned with the hot extrusion direction. The stringers of secondary phases provide evidence for their presence during the extrusion process, and therefore their stability at temperatures above $900{ }^{\circ} \mathrm{C}$. Attempts to solutionize and quench the alloys to a single-phase microstructure from higher temperatures were unsuccessful.

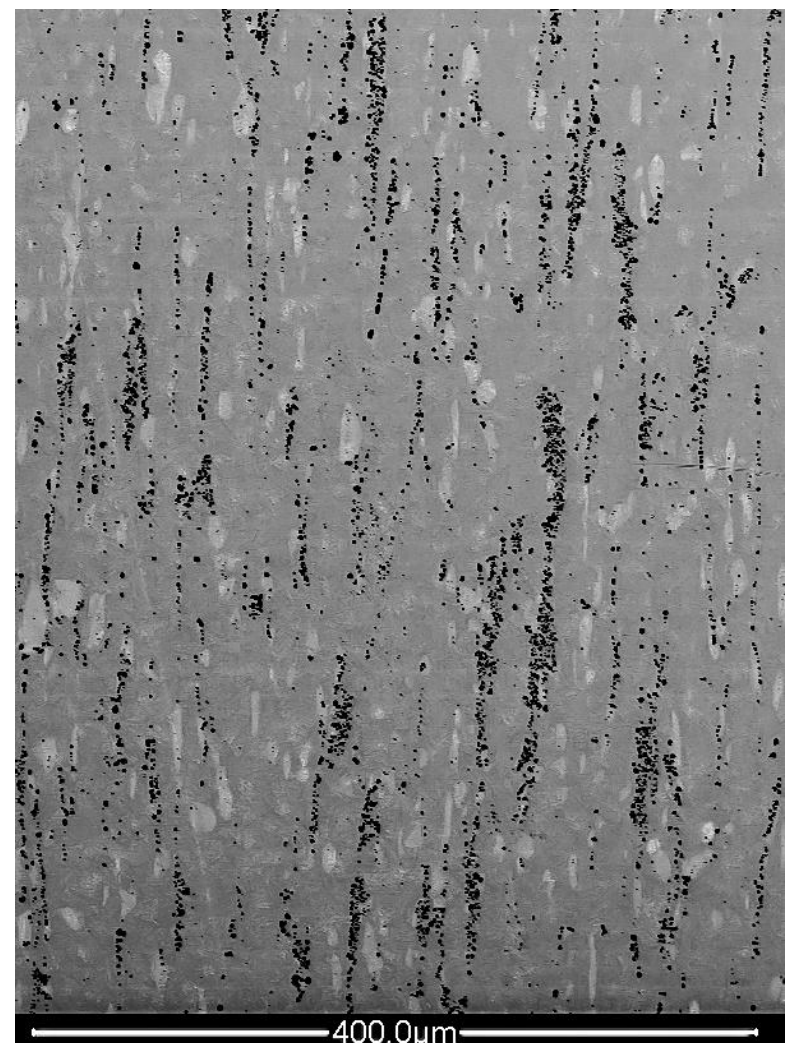

Figure 8: Longitudinal section SEM-BSE micrograph of the as-extruded 49Ti alloy. The extrusion direction is vertical. Note the second phase stringers (of both Type 1 and 2 as identified in Figure 7b) aligned in the vertical direction. 


\subsection{1 $\mathrm{Ti}_{3} \mathrm{Au}$ phase}

Confirmation of the structure of the phase identified above as $\mathrm{Ti}_{3} \mathrm{Au}$ was sought through more detailed STEM investigation. Significant intensity variations were observed within the $\mathrm{Ti}_{3} \mathrm{Au}$ phase, shown in bright-field TEM mode in Figure 9a, and HAADF STEM mode in Figures 9b and 9c. These regions were of the order of 2 to 10 $\mathrm{nm}$ in size. Initial concern was that these features might be the result of damage during FIB preparation, including possible Ga incorporation into the sample surfaces. However, these concerns were alleviated by investigation using thin-foil XEDS analysis, which yielded no correlation with $\mathrm{Ga}$ content. Furthermore, the samples were Nanomilled using low energy Ar ions, which should also remove FIB damage and near surface Ga incorporation, and yet the contrast seen in Figure 9 persisted.
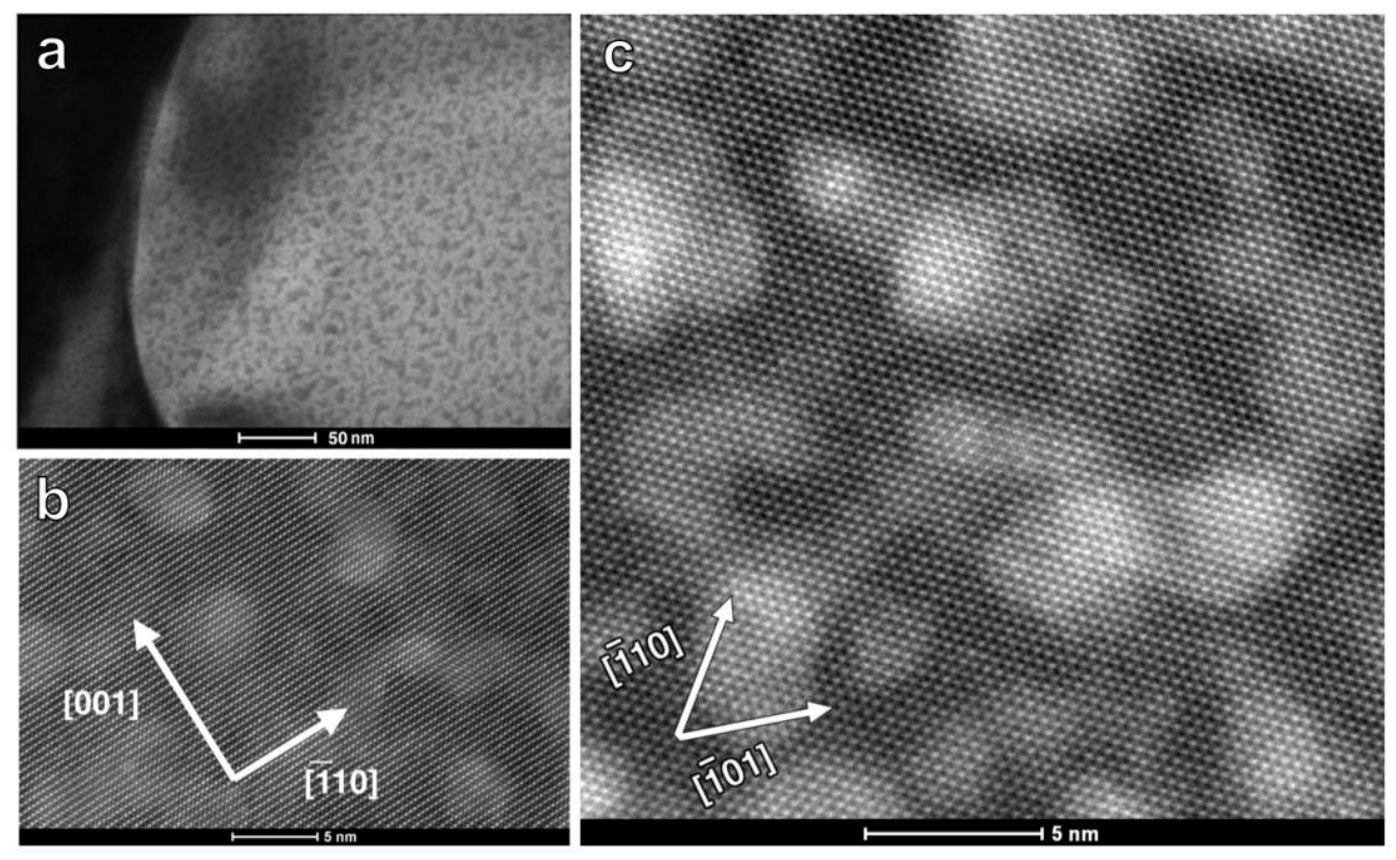

Figure 9: (a) BF-TEM and (b),(c) HAADF-STEM micrographs of the Ti, Au phase, highlighting widespread compositional segregation within a single precipitate.

HAADF STEM contrast depends on atomic number $\left(\sim Z^{2}\right)$; therefore, we can infer that the higher intensity regions are Au-rich, and the lower intensity regions are Ti-rich. This inference is fully supported by the high resolution XEDS chemical intensity maps, corresponding to the off-axis HAADF-STEM image of the modulated microstructure 
shown in Figure 10a. The XEDS maps shown in Figure 10b and 10c indicate Au-rich and Ti-rich regions that display a complementary spatial arrangement. As is evident from the HAADF STEM image in Figure 9c, these regions are perfectly coherent with the surrounding crystal, and all regions exhibit similar order contrast, supporting the likelihood that the compositional variation is the product of a spinodal decomposition. A line-scan across several regions, indicated in red in Figure 10a, is quantified in Figure $10 \mathrm{~d}$, with the corresponding area enlarged and shown below in Figure 10e. The sinusoidal oscillations of $\mathrm{Ti}$ and $\mathrm{Au}$ about their mean have a period on the order of $\sim 10$ $\mathrm{nm}$, further supporting the spinodal decomposition hypothesis, as this is within typical expected length-scale range for such a process [15].

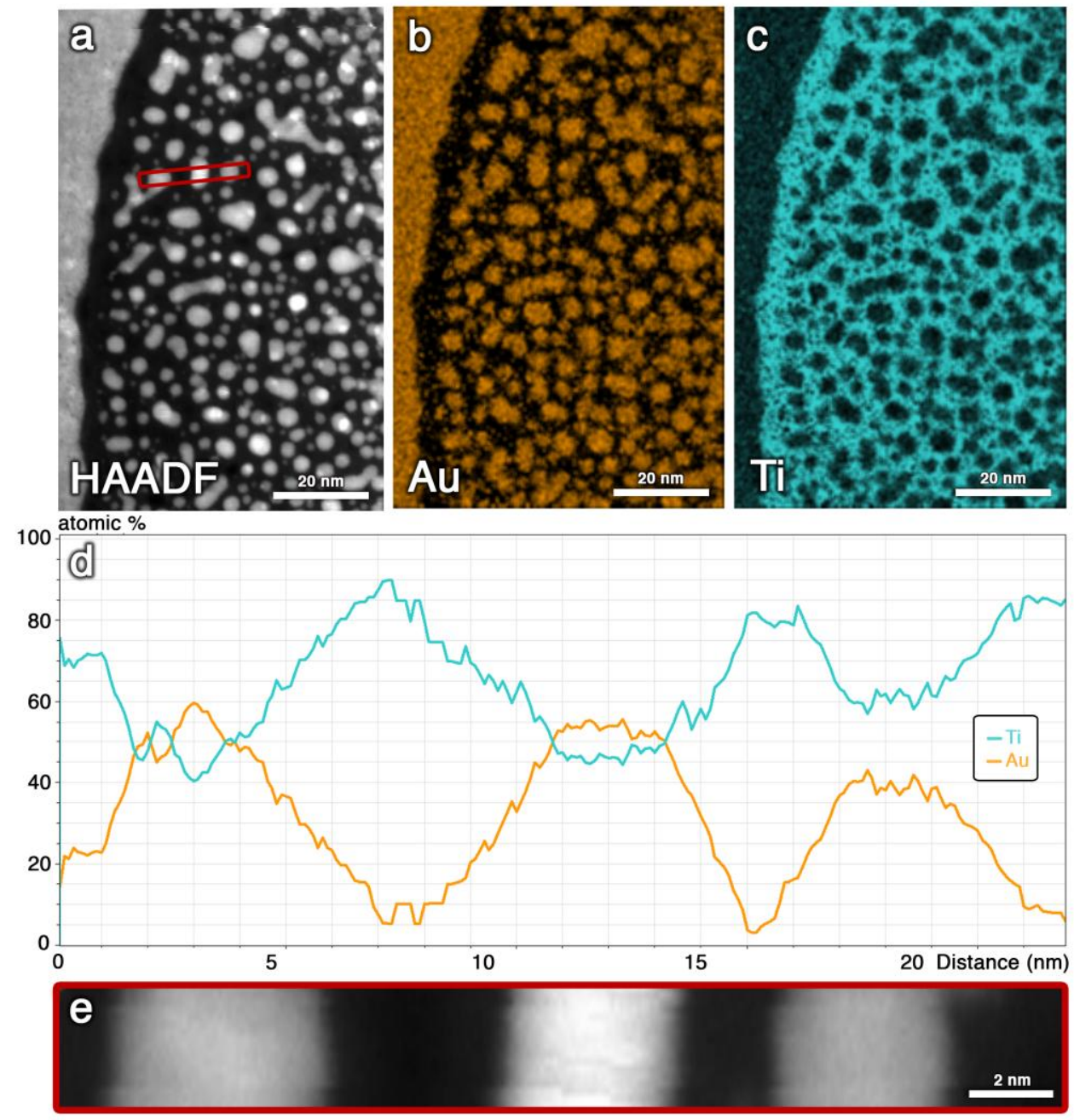

Figure 10: (a) Off-axis HAADF-STEM micrograph showing the nano-scale chemical fluctuations in the Ti ${ }_{3} A u$ phase. $(b, c)$ Super- $X^{T M}$ XEDS complementing chemical maps of Au and Ti, respectively. (d) Quantified line-scan of region shown in red in (a), and enlarged in (e) below. 
Diffraction analysis using TEM, combined with high resolution HAADF STEM imaging of the $\mathrm{Ti}_{3} \mathrm{Au}$ phase along several zone axes indicated a $\mathrm{Cu}_{3} \mathrm{Au} \mathrm{L}_{2}$ structure, with lattice parameter $a=0.41 \mathrm{~nm}$. These results are inconsistent with the $\mathrm{Cr}_{3} \mathrm{Si} \mathrm{A} 15$ structure commonly reported in the literature for $\mathrm{Ti}_{3} \mathrm{Au}[16,17]$. Several HAADF STEM images along prominent zone axes are shown in Figure 11, which support this conclusion. Although the $\mathrm{L}_{2}$ order contrast is continuously visible throughout the phase, the local composition variations indicate significant changes in sub-lattice occupancies, highlighted by the intensity differences between the two regions as exemplified below each zone axis in Figure 11.
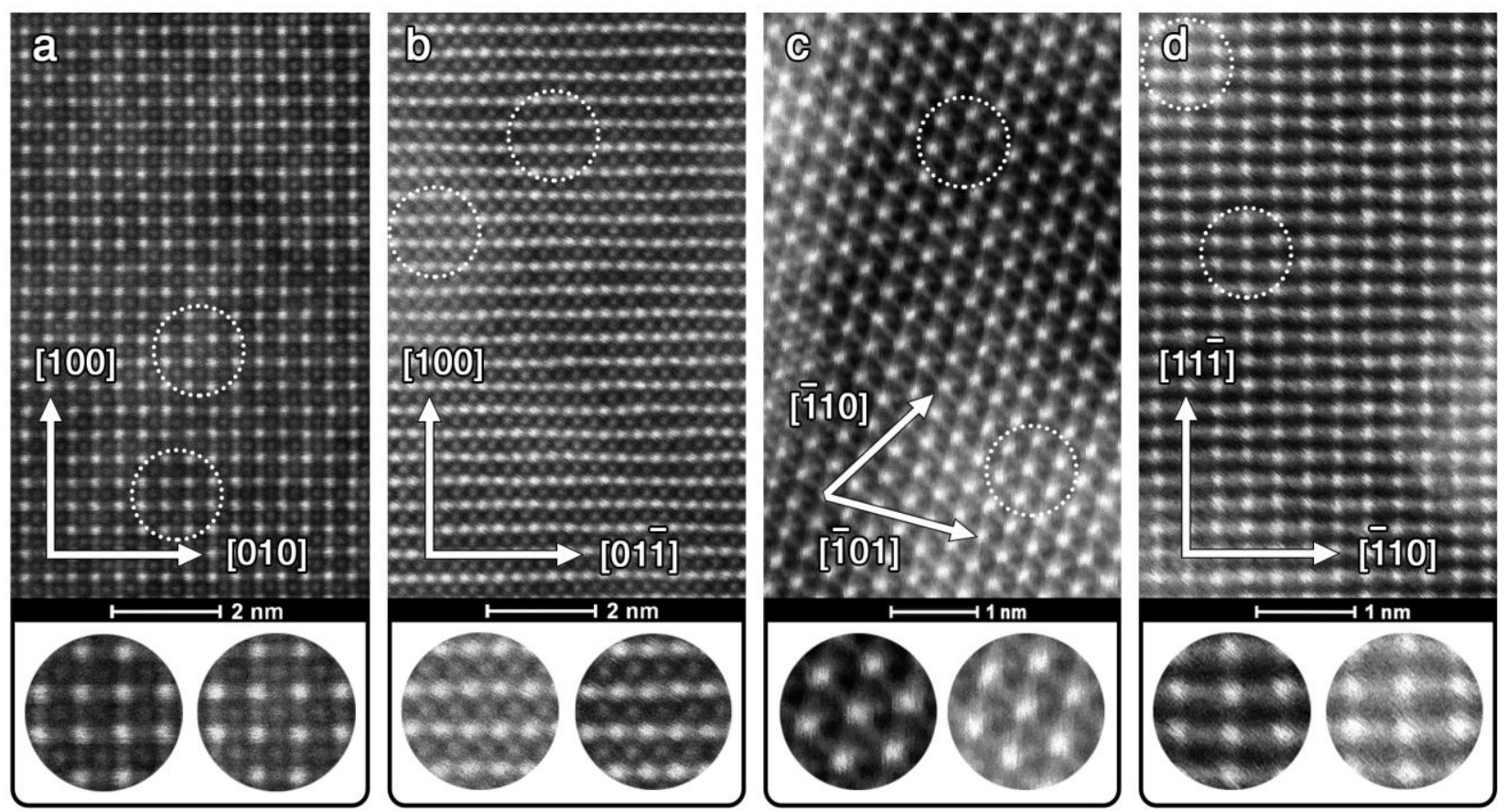

Figure 11: HAADF-STEM micrographs of the Ti $i_{3} A u$ phase along (a) [001], (b) [011], (c) [111], and (d) [112] zone axes, with enlarged insets to highlight differences in the $L 1_{2}$ order contrast. 


\subsection{2 $\mathrm{Ti}\left(\mathrm{Au}_{0.66} \mathrm{Ni}_{0.33}\right)_{2}$ phase}

Turning attention to the second phase, with apparent stoichiometry $\operatorname{Ti}_{3}\left(\mathrm{Au}_{4} \mathrm{Ni}_{2}\right)$, i.e. $\mathrm{Ti}\left(\mathrm{Au}_{0.66} \mathrm{Ni}_{0.33}\right)_{2}$, selected area diffraction (SAD) analyses provide evidence for a body-centered tetragonal crystal structure. Figure 12 shows diffraction patterns from several selected zone axes and the relationships between them. The tetragonality is evidenced by a mirror plane viewable down the main diagonal, containing the [331], [111], and [001] zone axis diffraction patterns.

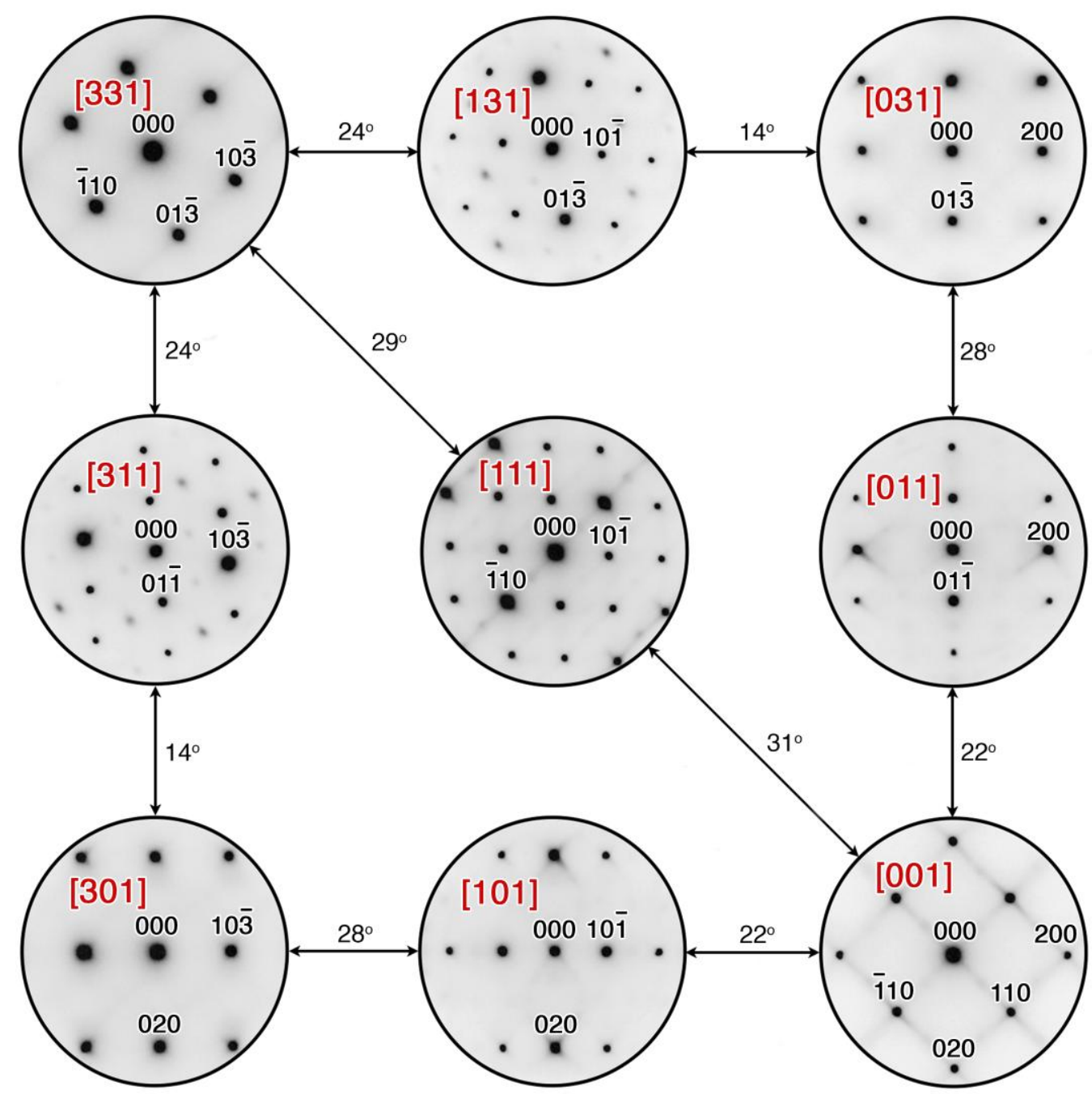

Figure 12: Selected area diffraction (SAD) patterns of the $\mathrm{Ti}\left(\mathrm{Au}_{0.66} \mathrm{Ni}_{0.33}\right)_{2}$ phase highlighting its tetragonal nature. 
Using extensive zone-axis HAADF-STEM imaging, as shown in Figure 13, where the brighter columns are likely Au-rich, the structure agrees closely with that of $\mathrm{TiAu}_{2}$, which has the $\mathrm{MoSi}_{2} \mathrm{c11}$ b structure [17-19]. This structure has a space group of $14 / \mathrm{mmm}$ and measured lattice parameters $\boldsymbol{a}=0.33 \mathrm{~nm}$ and $\boldsymbol{c}=0.83 \mathrm{~nm}$. Analogous structures have been reported in the NiTiCu and NiTiPd systems [20, 21].

It is assumed that the $\mathrm{Ni}$ and $\mathrm{Au}$ share the same lattice sites, however, making a definitive conclusion about the crystal structure from experimental observations alone is challenging. While the Au atomic columns are easily distinguishable in HAADF-STEM, $\mathrm{Ti}$ and $\mathrm{Ni}$ columns would have comparable intensities and would not be clearly distinguishable, making a full structural analysis difficult, especially at the modest volume fractions present. First principles DFT calculations could be pursued to further explore the energetics of the structure depending on site occupancy, but such a study is beyond the scope of the present paper.
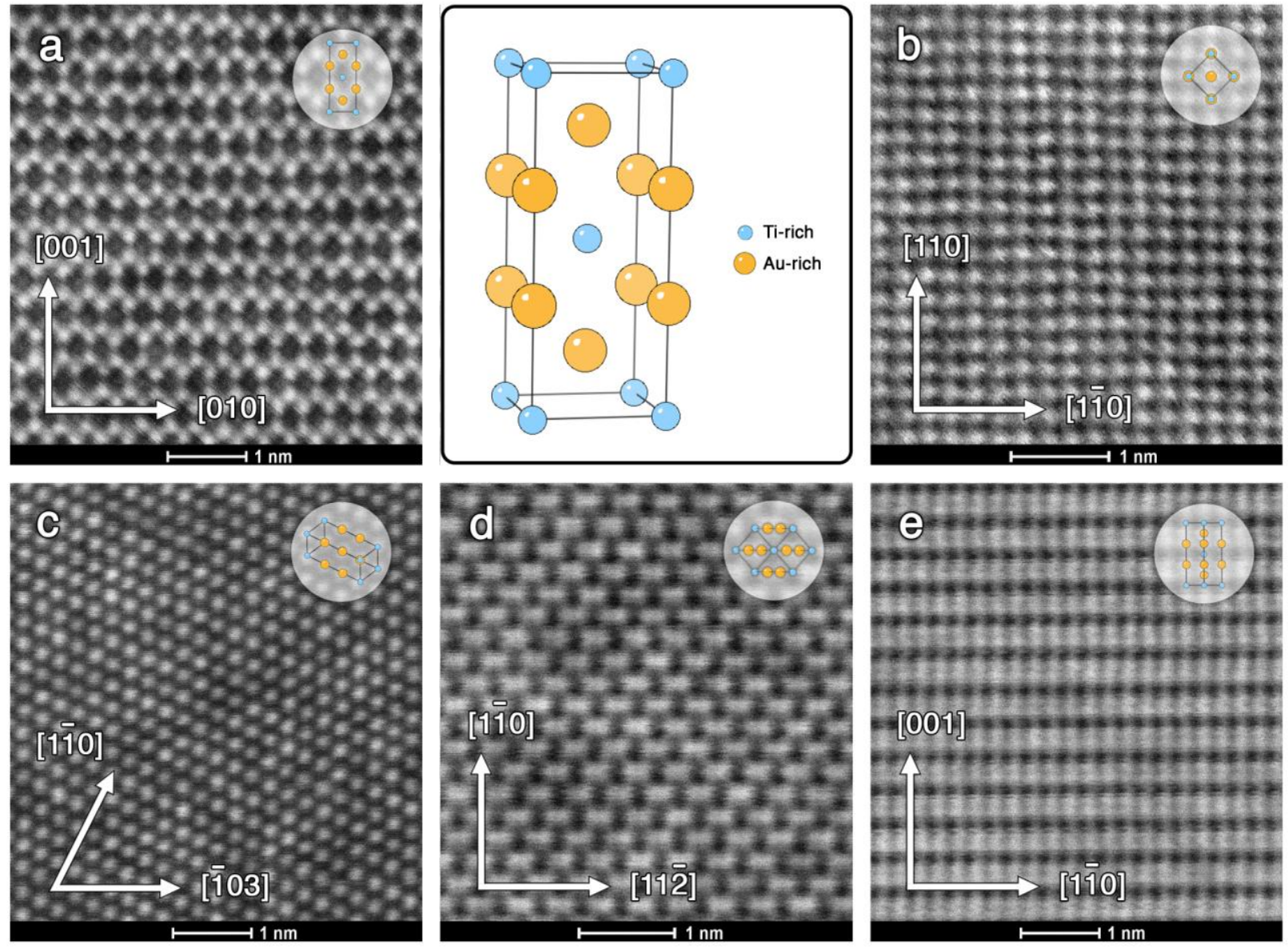

Figure 13: Zone-axis HAADF-STEM images of the Ti( $\left.A u_{0.66} \mathrm{Ni}_{0.33}\right)_{2}$ phase: (a) [100], (b) [001], (c) [331], (d) [111], (e) [110]. 


\section{Discussion}

\subsection{Load-biased thermal cycling behavior}

The four alloys studied have mechanical properties that are relatively insensitive to compositional variations. Also, uniquely, these alloys show isotropic behavior in tension and compression, with equivalent transformation strains being generated in tension and compression at equivalent stresses. The observed thermal cycling behavior was stable up to $150 \mathrm{MPa}$ in both tension and compression, above which significant unrecovered strain began to accumulate. The experiments performed did not evaluate stability for multiple cycles, nor the effect of time at temperature. The amount of work output observed was modest for all four alloys. This was largely a result of the relatively small transformation strains measured. Although the theoretical maximum transformation strain is lower for B19 than for B19' martensite [22], other HTSMAs with a B19 matrix [23] have shown superior behavior; for example, the comparison with NiTiPd alloys shown in Figure 14. However, there is at least a $200{ }^{\circ} \mathrm{C}$ difference in upper cycle test temperature for these two sets of data. Figure 15 shows a comparison of work output with respect to $M_{\mathrm{s}}$ for NiTi-40Au with various NiTiPd and NiTiPt alloys. While higher stress-free $M_{\mathrm{s}}$ temperatures have certainly been recorded for other ternary systems - in excess of $1000{ }^{\circ} \mathrm{C}$ for some NiTiPt alloys [24] - their work output rapidly drops to zero at temperatures higher than $400{ }^{\circ} \mathrm{C}[23]$.

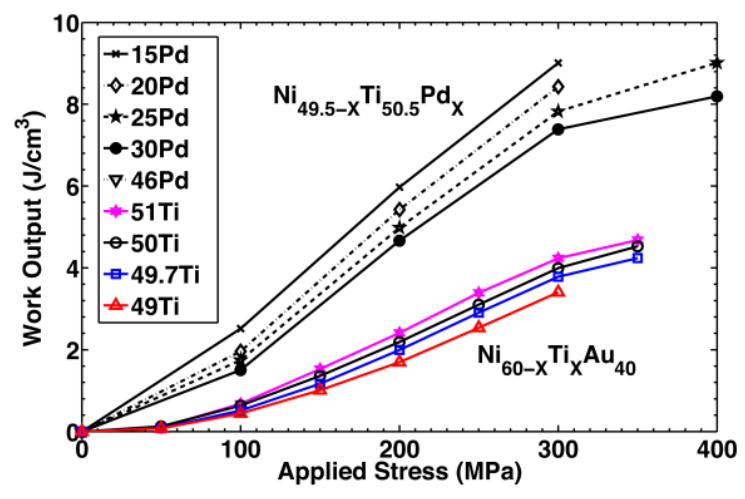

Figure 14: Work output vs. applied stress comparison between the NiTi-40Au alloys with various NiTiPd alloys from [31].

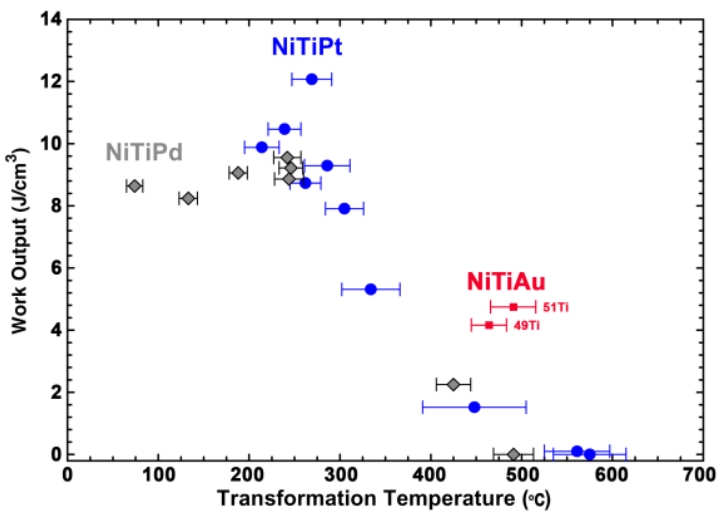

Figure 15: Work output vs. $M_{s}$ comparison for three HTSMA systems (data for NiTiPt and NiTiPd from [23]). 


\section{2 $\mathrm{Ti}_{3} \mathrm{Au}$ phase structure}

It is interesting that in our NiTiAu alloys this phase exhibits the $L 1_{2}$ structure, since the $\mathrm{A} 15$ structure is commonly reported in the literature for $\mathrm{Ti}_{3} \mathrm{Au}$. Donkersloot and van Vucht [4] observed $\mathrm{TiAu}_{2}$ forming on the Au-rich side, and $\mathrm{Ti}_{3} \mathrm{Au}$ on the Au-lean side in binary TiAu alloys. They noted that the $\mathrm{Ti}_{3} \mathrm{Au}$ initially precipitated with the $\mathrm{A} 15$ structure, but after prolonged heat treatment, it was partially replaced by $L 1_{2} \mathrm{Ti}_{3} \mathrm{Au}$. This has been hypothesized to be a result of impurity atoms, which stabilize the $\mathrm{L}_{2}$ structure, proposed by von Philipsborn and Laves [25], who demonstrated that $\mathrm{L}_{2}$ $\mathrm{Ti}_{3} \mathrm{Au}$ formed in the presence of small amounts of carbon, oxygen or nitrogen.

\subsection{Secondary phase fraction}

The secondary phase content varies for each composition. SEM backscatter micrographs of representative regions are shown in Figure 16a. Phase fractions were calculated from $2 \mathrm{D}$ segmentation maps created using the MIPAR ${ }^{\mathrm{TM}}$ image processing software package [26]. Results from multiple sampling regions in each alloy are presented in Figure 16b.

It should be noted that the Ti-rich $\mathrm{Ti}_{3} \mathrm{Au}$ phase is present for all Ti-lean compositions, and does not appear to vary significantly between the 49Ti, 49.7Ti and $50 \mathrm{Ti}$ alloys. The $\mathrm{Ti}_{3} \mathrm{Au}$ phase fraction increases only for the Ti-rich $51 \mathrm{Ti}$ alloy to $\sim 4.3 \%$ from $3 \%$ for the other three alloys.

The amount of $\mathrm{Ti}\left(\mathrm{Au}_{0.66} \mathrm{Ni}_{0.33}\right)_{2}$ is likely dictated by alloy composition and the degree to which the alloys are $\mathrm{Ni}+\mathrm{Au}$ rich. The volume fraction decreases from $\sim 9.3$ to $4.9 \%$ as the $\mathrm{Ni}+\mathrm{Au}$ content decreases from 51 to 50 at.\%. Once the composition turns $\mathrm{Ti}$ rich, the phase is no longer observed and drops essentially to zero. 

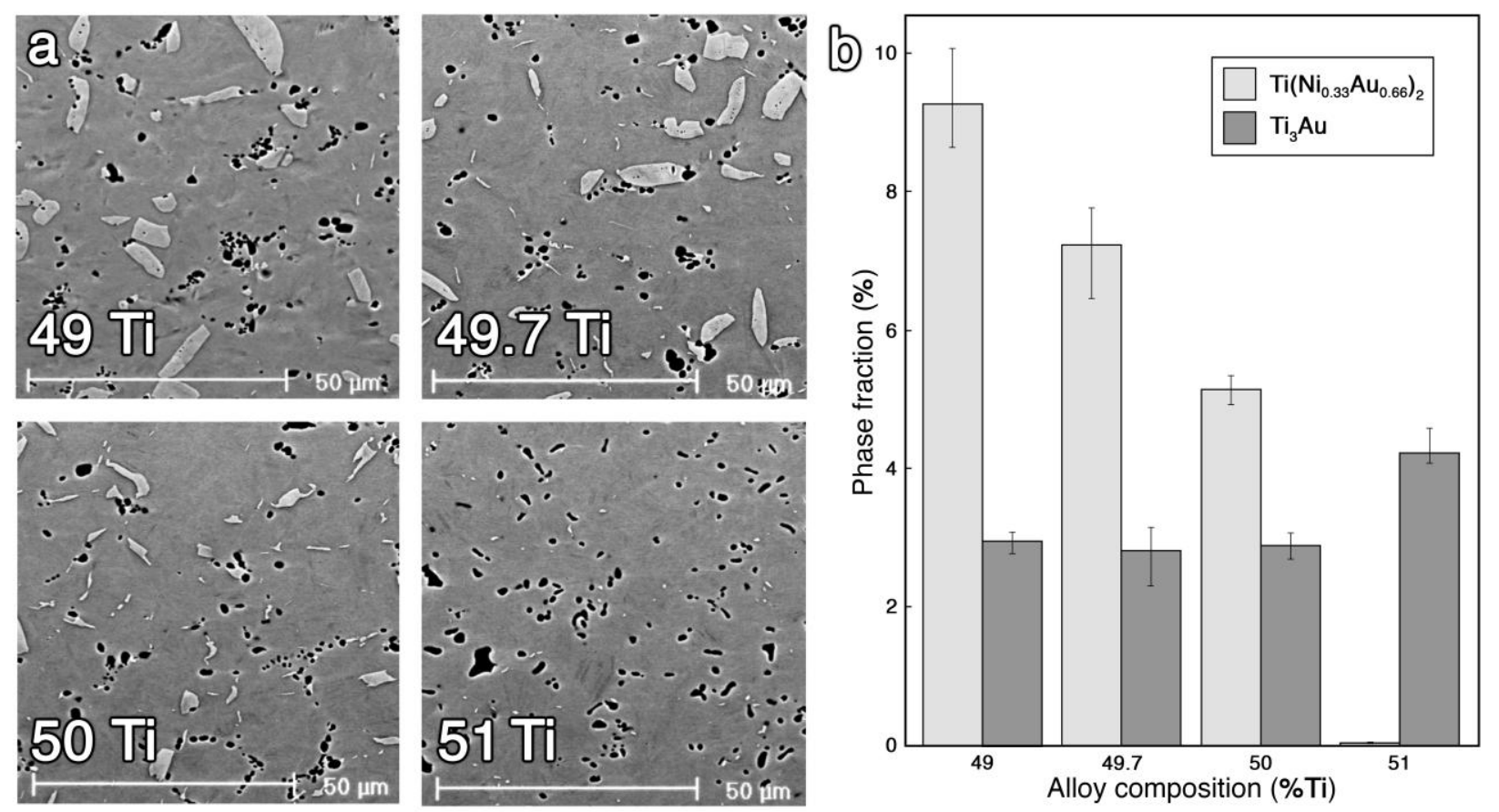

Figure 16: (a) Comparison of as-extruded, transverse section microstructures in BSE-SEM.

(b) Secondary phase fractions in each alloy. 
If the varying secondary phase content does in fact help maintain a near constant matrix composition, it may explain why the differences in $M_{\mathrm{s}}$ and load-biased thermal cycling behavior are so minor between Ti-lean and Ti-rich alloy compositions. This behavior is unique to the NiTiAu system, in comparison to the strong dependence of composition on $M_{\mathrm{s}}$ exhibited by many other NiTi based SMAs for similar compositional variations [2, 22].

In order to evaluate the matrix composition across the four alloys, XEDS data from multiple matrix regions were corrected in three different ways for comparison purposes. Since the compositional differences are already so small between the alloys, it is difficult to make detailed quantitative conclusions; however, trends are certainly observable and support a moderating effect of the second phases on matrix composition.

To improve on the raw XEDS data, the first correction applied utilized k-factors that were generated from large area SEM scans, where the resulting intensity ratios were assumed to be representative of overall alloy composition. The second correction used the $\mathrm{Ti}\left(\mathrm{Au}_{0.66} \mathrm{Ni}_{0.33}\right)_{2}$ phase as a standard for new k-factors, with the assumption the phase is a line compound of uniform composition, and that the interaction volume did not include surrounding regions. The third correction attempt used the phase fraction data from Figure $16 \mathrm{~b}$, together with assumed phase stoichiometry and overall alloy compositions to back-calculate the resulting matrix composition.

The results for the $\mathrm{Ni}$ and $\mathrm{Ni}+\mathrm{Au}$ content of the matrix are shown in Figure 17. The observed trends show a clear moderating effect of secondary phase content on matrix composition. Thus, all three correction approaches are consistent with the hypothesis that the matrix composition maintains a relatively constant composition for all four alloys. This result is to be expected for an equilibrium, three-phase microstructure in which the phase fractions may vary but the compositions of the phases remain constant as a function of overall alloy composition. While the present results do not fully demonstrate a constant $\mathrm{Ni}+\mathrm{Au}$ value, the moderating effect of the two phases on the matrix composition has been demonstrated to the accuracy presently possible with this XEDS-based approach.

The transformation strains exhibited by the four alloys appear to vary in a 
sensible way with the total volume fraction of the matrix phase. An increase in matrix volume fraction from approximately $88 \%$ to $96 \%$ corresponds to an increase in transformation strain from $1.25 \%$ to $1.5 \%$, as can be seen by comparing figures 3 and 16.
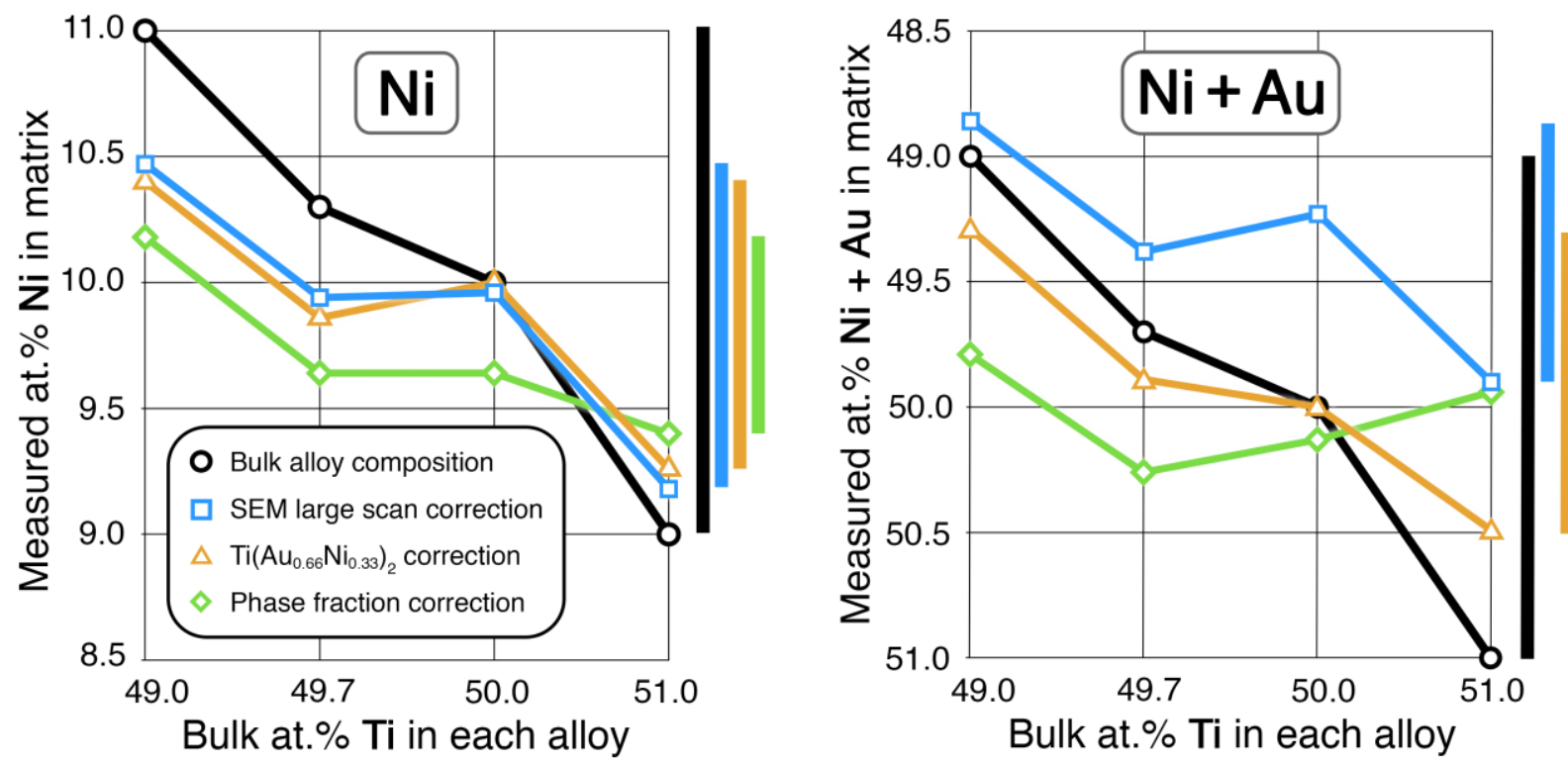

Figure 17: Measured matrix Ni content and Ni+Au content for each alloy as a function of bulk alloy Ti content. The data suggest a moderating effect of secondary phase content on matrix composition compared to bulk alloy composition. 
While these TiNi-40Au alloys exhibit very promising shape memory behavior and very high $M_{\mathrm{s}}$, the transformation strains will likely need to be raised to improve alloy viability for general application. This could potentially be achieved through training, texturing, or tailoring secondary phase content [22]. However, the inability to solutionize these alloys may prove to be a significant impediment to second phase modification. Nevertheless, the relative insensitivity to alloy composition exhibited by these alloys, in contrast to all other HTSMA systems, means that these alloys may be amenable to processing routes where precise control of composition is difficult (e.g., thin film techniques using multiple sputtering sources or typical additive manufacturing approaches).

\subsection{Theoretical analysis of martensitic transformation in NiTiAu}

In Figure 4, notable unrecovered strains are present with each thermal cycle, particularly at stresses greater than $150 \mathrm{MPa}$. The amount of unrecovered strain strongly depends on the biasing load, e.g., almost nil (0.03\%) at $100 \mathrm{MPa}$ and as much as $\sim 1 \%$ at $400 \mathrm{MPa}$ in compression. As reported by Bowers, et al. in their study of binary $\mathrm{NiTi}$ [27], the amount of unrecovered strain depends on not only the magnitude of the biasing load but also the number of thermal cycles performed. For example, unrecovered strain may approach $10 \%$ after 100 thermal cycles under a $150 \mathrm{MPa}$ biasing load in $\mathrm{NiTi}$, resulting from the generation and accumulation of considerable crystalline defects, including dislocations and grain boundaries.

The generation of these defect structures during transformation cycling degrades the alloy performance, leading to what is commonly termed "functional fatigue". Recently, this phenomenon has been theoretically investigated through pathway analysis of the martensitic transformation [27-30], and a similar approach is described here for the B2 to B19 transformation in NiTiAu. In fact, three NiTi-based HTSMA systems are compared to better understand the mechanism(s) associated with unrecovered strain in the NiTiAu alloys, i.e., NiTiAu, NiTiPd and NiTiPt, all of which 
undergo the B2 to B19 martensitic transformation. Note that the broken symmetry during the B2 to B19 transformation is different from that during the B2 to B19' (monoclinic) transformation in the NiTi binary system, so one cannot expect the same pathway mechanism as described previously by Bowers, et al [27]. However, the concept of symmetry-dictated non-phase-transformation pathway (SDNPTP) [27, 28] can still be utilized. In the B2 to B19' transformation, a sequential transition from initial B2 to B19' to an alternate B2 is identified according to the energetic and geometrical closeness between B19' and a base-centered orthorhombic (BCO) structure. A similar analysis indicates that the crystal structure of B19 is geometrically similar to an HCPbased ordered structure, and the associated pathway is parallel to the well-known Burgers path proposed for the BCC to HCP transformation. For example, lattice parameters of B19 in NiTiPt $\left(\mathrm{Ni}_{30} \mathrm{Ti}_{50} \mathrm{Pt}_{20}\right)$ are $\mathbf{a}=0.275 \mathrm{~nm}, \mathbf{b}=0.470 \mathrm{~nm}, \mathbf{c}=0.444 \mathrm{~nm}$ [31], so that b/a and c/a ratios are 1.71 and 1.61, respectively, which is close to those of a perfect HCP structure (HCP can be regarded as a special orthorhombic case with b/a $=1.732$ and $\mathbf{c} / \mathbf{a}=1.633)$. By ignoring the atomic ordering initially, we propose $a$ transformation sequence during thermal cycling from an initial BCC state to an orthorhombic state and then back to a new BCC state (Figure 18). A schematic illustration of such a transformation mechanism is shown in Figure 18(a). From the initial BCC to HCP, a $\{110\}$ plane in BCC transforms to the basal plane in HCP, and the aspect ratio of the rectangle circled by the red dashed line changes from $\sqrt{2}$ to $\sqrt{3}$. From the HCP to the new BCC during the reverse transformation, the aspect ratio of the rectangle circled by the green dashed line changes from $\sqrt{3}$ to $\sqrt{2}$. It is clear that the initial BCC and the new BCC states are distinctively different structural states and the transition between them is associated with a lattice distortion and leads to the generation of dislocations and grain boundaries.

During thermal cycling, the transformation pathway from BCC to orthorhombic is activated by the driving force for the transformation (i.e., undercooling). The SDNPTP between two orthorhombic structures could be activated by both internal and external stresses, especially when a biasing load is applied. Whether or not defects are generated during cycling is determined by whether or not the SDNPTP is activated. Because of the lack of energetic data, we compare the activation energies of SDNPTPS 
in NiTiAu (40Au), NiTiPd (30Pd) and NiTiPt (30Pt) HTSMA systems from a purely geometrical point of view. According to lattice parameters of the orthorhombic martensite in the three alloys [31-34], the b/a ratio is $1.58,1.61$ and 1.71 for NiTiAu, $\mathrm{NiTiPd}$, and NiTiPt, respectively, which suggests a geometrical similarity between the orthorhombic and HCP (1.732) structures. It is reasonable to assume that the closer the two structures, the lower the activation energy barrier would be for the SDNPTPs [35]. Therefore, one should expect a functional fatigue resistance ranking among the three alloys of NiTiAu > NiTiPd > NiTiPt. As reported in the literature [31-33], under a 200 $\mathrm{MPa}$ tensile stress, the unrecovered strains after one cycle for the three alloys (unaged and untrained) are $\sim 0.1 \%, \sim 0.4 \%, \sim 1 \%$, respectively, in agreement with this pathway analysis.

Atomic ordering in B2 will also play a role in the proposed pathway mechanism. As shown in Figure 18(b), when the transformation cycling starts from a B2 structure, the new structural state produced by the reverse transformation from B19 is no longer B2, nor is it at the same energetic level as that of B2. Theoretically, if such a new BCCbased ordered structure were thermodynamically stable, the generation of new phase domains could be expected with thermal cycling. If it is unstable, dislocations and antiphase domain boundaries would be generated during cycling. The above predictions of defect structures run parallel to those made for the NiTi binary system [27], in which both dislocations and special grain boundaries are predicted and observed experimentally. However, because the pathway in this case is associated with the translational symmetry broken by $\mathrm{B} 2$ ordering $(1 / 2<111>$ translation), anti-phase domain boundaries will be generated during the B2 to B19 transformation cycling, which is in contrast to that of the B2 to B19' transformation. Quantitative prediction and characterization of defect structures generated during thermal cycling of the B2 to B19 transformation is underway and will be reported in a separate paper.

Finally, while the pathways analysis indicates that the functional fatigue of NiTiAu is theoretically better than other precious metal containing HTSMA (i.e., NiTiPd and $\mathrm{NiTiPt}$ ), which is a very promising result, the strength of the austenite phase at higher temperatures appears to be the primary limitation for this high-temperature shape memory alloy. It is evident from Figures 1 and 2 that at temperatures greater than about 
$480{ }^{\circ} \mathrm{C}$ and particularly at stresses greater than about $300 \mathrm{MPa}$ the NiTiAu alloys plastically deform or creep, which causes a significant increment in unrecoverable strain in the direction of the applied stress, after the transformation. This permanent deformation is not associated with the transformation, but due to plastic and viscoplastic deformation of the austenite phase similar to what has been observed in some detail in the NiTi-30Pd system [36, 37]. This NiTiPd alloy actually undergoes moderate creep at $400{ }^{\circ} \mathrm{C}$ and stresses above $100 \mathrm{MPa}$ resulting in a similar "hump" in the stresstemperature curves at temperatures above the transformation, similar to what is observed in the NiTiAu alloys in Figures 1 and 2. Consequently, while a promising shape memory alloy for very high temperature applications, these NiTi-40Au alloys still need to be modified to improve austenite creep strength before they can be used reliably at moderate stresses for multiple cycles. 


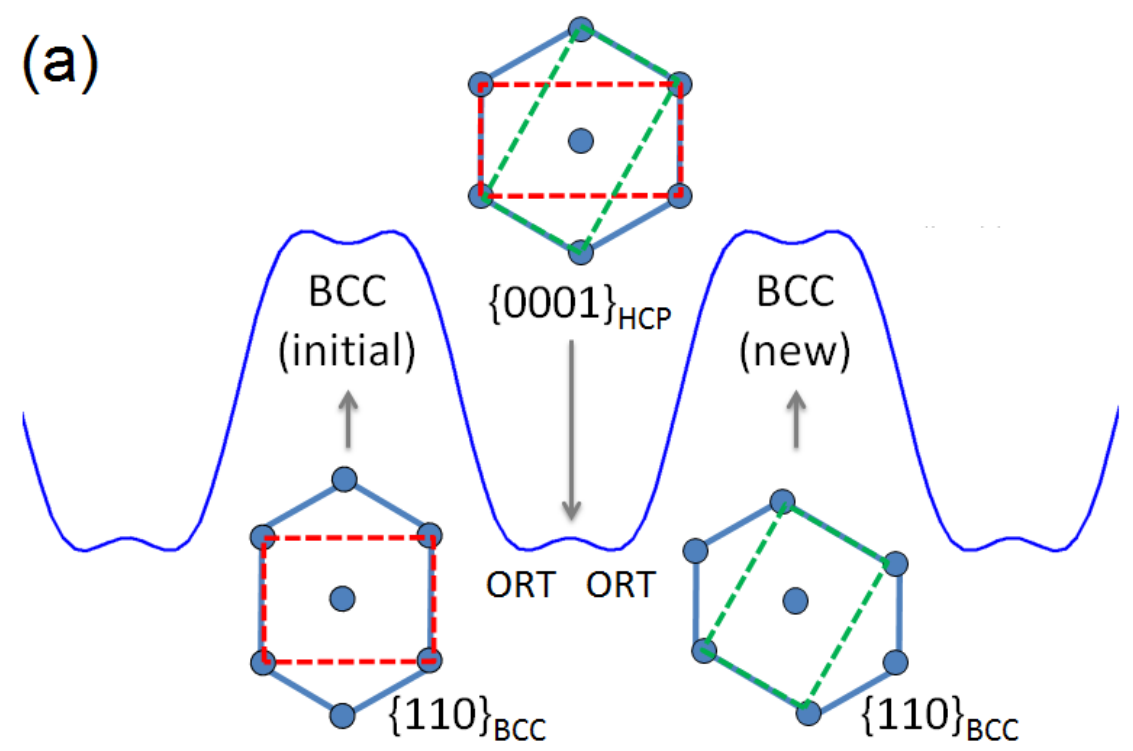

(b)

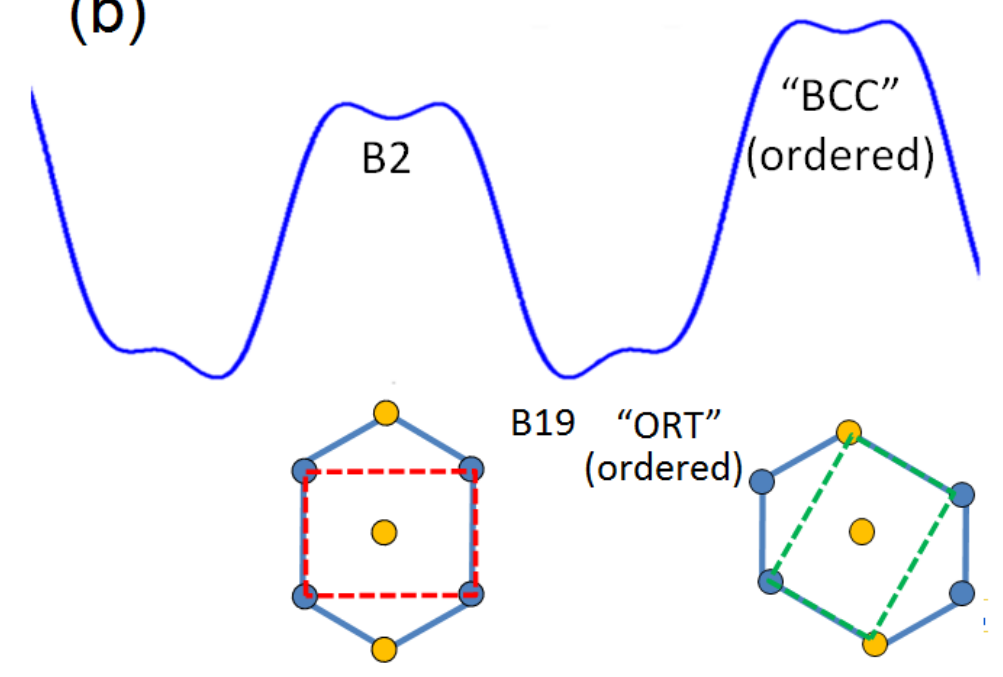

Figure 18: Schematic of the pathway and energy landscape during transformation cycling of (a) $B C C$ to orthorhombic; (b) B2 to B19. 


\section{Conclusions}

Four alloys of NiTi-40Au were evaluated using load-biased thermal cycling experiments, SEM, HAADF-STEM, and XEDS. Load-biased thermal cycling behavior showed notable work output above $400{ }^{\circ} \mathrm{C}$, behavior not previously observed in any NiTi-based HTSMAs. Shape memory behavior was largely unaffected by changes in alloy composition from 49Ti to 51Ti. This was likely caused by the presence of two types of secondary phases, $\mathrm{Ti}_{3} \mathrm{Au}$ and $\mathrm{Ti}\left(\mathrm{Au}_{0.66} \mathrm{Ni}_{0.33}\right)_{2}$, which have a moderating effect on matrix composition. The $\mathrm{Ti}_{3} \mathrm{Au}$ phase has an $\mathrm{L}_{2}$ structure, with lattice parameter a $=0.41 \mathrm{~nm}$, not the $\mathrm{Cr}_{3} \mathrm{Si} \mathrm{A15}$ structure previously reported in the literature. The $\mathrm{Ti}\left(\mathrm{Au}_{0.66} \mathrm{Ni}_{0.33}\right)_{2}$ phase has a $\mathrm{c} 11 \mathrm{~b}$ tetragonal structure with lattice parameters $\mathbf{a}=0.33$ $\mathrm{nm}, \mathbf{c}=0.83 \mathrm{~nm}$. Crystallographic pathway analysis provided a theoretical perspective of the defect formation mechanisms leading to unrecovered strain due to cycling through the transformation and the consequent functional fatigue, and indicates that the NiTiAu system should be superior to other B2-to-B19 transformation systems, particularly if the creep strength of the austenite phase can be improved.

\section{Acknowledgements}

LC, YG, YW, and MJM have been supported in this work by Award \#DE-SC0001258 from the Department of Energy, Office of Basic Sciences under the Nanostructure Alloys and Radiation Effects Program, Dr. John Vetrano Program Manager. GSB, OB, and RDN acknowledge the support of the NASA Transformative Aeronautics Concepts Program, Transformational Tools \& Technologies Project. 


\section{References}

1. R.D. Noebe, T. Biles, and S.A. Padula: Advanced Structural Materials: Properties, Design Optimization, and Applications, Taylor \& Francis CRC Press, Boca Raton, FL, 2007, pp. 145-186.

2. J. Ma, I. Karaman, and R.D. Noebe: Int. Mater. Rev., 2010, vol. 55, pp. 257-315.

3. S. Miyazaki, Y.Q. Fu, and W.M. Huang: Thin film shape memory alloys: fundamentals and device applications, Cambridge University Press, Cambridge,UK, 2009.

4. H. Donkersloot and J. van Vucht: J. Less Common Met., 1970, vol. 20, pp. 83.

5. K. Eckelmeyer. Scr. Metall.: 1976, vol. 10, pp. 667-672.

6. S.K. Wu and C.M. Wayman: Metallography, 1987, vol. 376, pp. 359.

7. S.K. Wu and C.M. Wayman: Mater. Sci. Eng. A, 1987, vol. 96, pp. 295.

8. S.K. Wu and C.M. Wayman: Scr. Mater., 1987, vol. 21, pp. 83.

9. H. Hosoda, R. Tachi, T. Inamura, K. Wakashima, and S. Miyazaki: Materials Science Forum, 2007, vol. 561, pp. 1541

10.S. Besseghini, F. Pssaretti, E. Villa, P. Fabbro, and F. Ricciardi: Gold Bull 2007, vol. 40 , pp. 328.

11.R.D. Noebe, D.J. Gaydosh, S.A. Padula, A. Garg, T. Biles, and M. Nathal: Proc. SPIE, 2005, vol. 5761, pp. 364-375.

12. D J Hartl, J H Mabe, O Benafan, A Coda, B Conduit, R Padan and B Van Doren: Smart Mater. Struc., 2015, vol. 24, pp.1-6.

13.L. Orgeas and D. Favier: J. Phys., 1995, vol. 5, pp. 605-610.

14. H. Sehitoglu, R. Hamilton, D. Canadinc, X.Y. Zhang, K. Gall, I. Karaman, Y. I. Chumlyakov, and H. J. Maier: Metall. Mater. Trans. A, 2003, vol. 34, pp. 5.

15.F.C. Campbell: Phase Transformations: Understanding the Basics, ASM International, Materials Park, OH, 2012.

16.P. Duwez and C. B. Jordan: Acta Cryst., 1952, vol. 5, pp. 213.

17.J.L. Murray: Bull. Alloy Phase Diagrams, 1983, vol. 4, pp. 278-283. 
18. E. Stolz and K. Schubert: Metallkd., 1962, vol. 43, pp. 433-444.

19.P. Pietrowsky: J. Inst. Met., 1962, vol. 90, pp. 434-438.

20.F.J.J. van Loo, G.F. Bastin and A.J.H. Leenen, J. Less Common Met., 1978, vol. 57, pp. 111.

21.R. Delville and D. Schryvers: Intermet., 2010, vol. 18, pp. 2353-2360.

22. K. Otsuka and X. Ren: Prog. Mater. Sci., 2005, vol. 50, pp. 511-678.

23. S.A. Padula, G.S. Bigelow, R.D. Noebe, D.J. Gaydosh and A. Garg: Proc. SMST, 2006, pp. 787-802.

24. O. Rios, R.Noebe, T. Biles, A. Garg, A. Palczer, D. Scheiman, H.J. Seifert and M. Kaufman: Proc. SPIE, 2005, vol. 5761, pp. 376-387.

25. H. von Philipsborn and F. Laves: Acta Cryst., 1964, vol. 17, pp. 213.

26. J.M. Sosa, D.E. Huber, B. Welk and H.L. Fraser: IMMI, 2014, vol. 3, pp. 1-18.

27. M. L. Bowers, Y. Gao, L. Yang, D. J. Gaydosh, M. De Graef, R. D. Noebe, Y.

Wang, M. J. Mills: Acta Mater, 2015, vol. 91, pp. 318-329.

28. Y. Gao, L. Casalena, M. L. Bowers, R. D. Noebe, M. J. Mills, Y. Wang: Acta Mater, accepted manuscript, http://dx.doi.org/10.1016/j.actamat.2017.01.001 .

29. Y. Gao, N. Zhou, D. Wang, Y. Wang: Acta Mater, 2014, vol. 68, pp. 93-105.

30.K. Bhattacharya, S. Conti, G. Zanzotto, J. Zimmer: Nature, 2004, vol. 428, pp. 55-59.

31. R. D. Noebe, D. Gaydosh, S. A. Padula II, A. Garg, T. Biles, M. Nathal: Proc. SPIE 5761, 2005.

32. G. S. Bigelow, S. A. Padula II, A. Garg, D. Gaydosh, R. D. Noebe: Metall Mater Trans A, 2010, vol. 41, pp. 3065-3079.

33. R. D. Noebe, S. Draper, D. Gaydosh, A. Garga, B. Lerch, N. Penney, G. S. Bigelow, S. A. Padula II, J. Brown: Proc. SMST, 2006, pp. 409.

34. Y. Gao, N. Zhou, F. Yang, Y. Cui, L. Kovarik, N. Hatcher, R. Noebe, M. J. Mills, Y. Wang: Acta Mater, 2012, vol. 60, pp. 1514-1527.

35.J. S. Bowles: Acta Cryst, 1951, vol. 4, pp. 162-171. 
36.J.A. Monroe, I. Karaman, D.C. Lagoudas, G. Bigelow, R.D. Noebe, and S. Padula, Scripta Mater., 2011, vol. 65, pp. 123-126.

37. P.K. Kumar, U. Desai, J.A. Monroe, D.C. Lagoudas, I. Karaman, G. Bigelow, and R.D. Noebe, Mater. Sci. Eng. A, 2011, vol. 530, pp. 117-127. 